ص ص [271-257

$$
\begin{aligned}
& \text { دراسة عن هدم الدور التزاثية في مدينة الموصل } \\
& \text { (در اسة اجتماعية - (قتصادية) }
\end{aligned}
$$

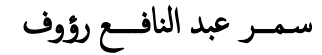

$$
\begin{aligned}
& \text { مدرس مساعد-قسم إدارة الأعمال } \\
& \text { كلية الإدارة والاقتصاد-جامعة الموصل }
\end{aligned}
$$

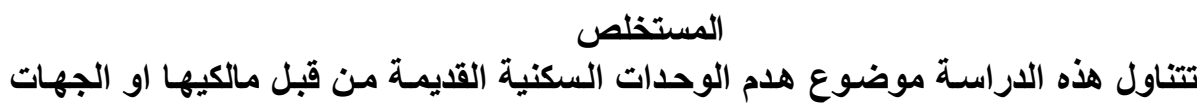

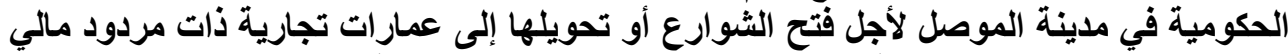

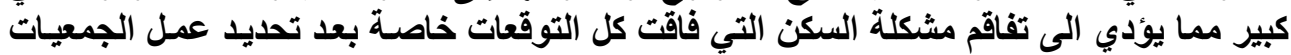

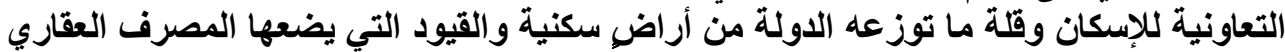

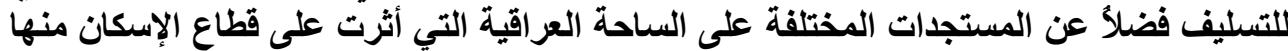

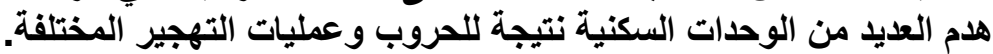

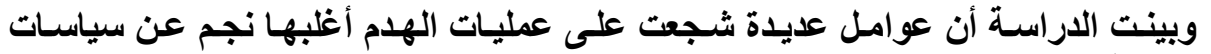

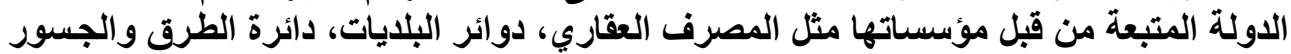

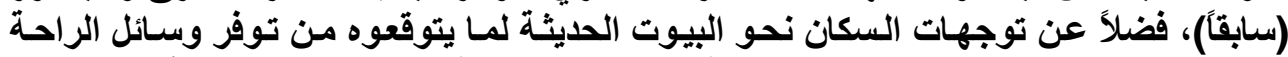

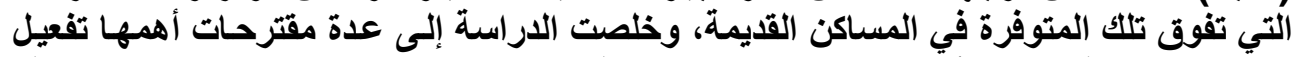

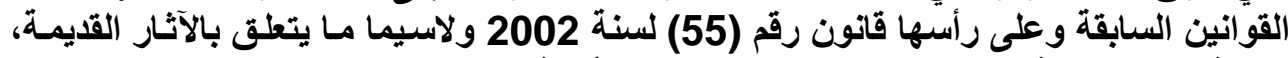

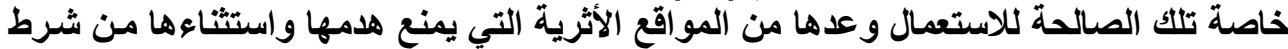

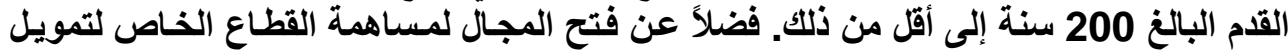

\title{
A Study about the Demolition of Traditional Houses in Mosul (Social and Economical Study)
}

Samar A. N. Raoof

Assistant Lecturer

University of Mosul

\begin{abstract}
Housing is an important basic need that is closely related to the process of change and development. The housing activity is complex and has important historical dimensions. As a process housing is not only concerned with the number of dwellings available, but in fact
\end{abstract}


is a part of the total social and political milieu of society. The housing unit itself is a complex commodity that has a different function to the many people involved; in its design, production, exchange, distribution and use. Housing also forms a large part of the urban activities .The study of housing embodies many of the urban complexities. The research is an attempt to reveal the problems that arose from destroying traditional buildings, especially those used for dwelling. In spite of the many regulations issued before the year 2003, the problem is still aggravating either because the regulations were concerned only with the historical buildings or with traditional houses exceeding 200 years old, and a third reason might be the negligence to employ these regulations. The treatment of this problem will certainly help to cure present unemployment and also will help in developing more than (80) economical fields. The research is concluded with a number of relevant and quite applicable recommendations.

المقدمة

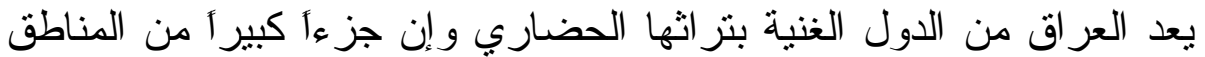

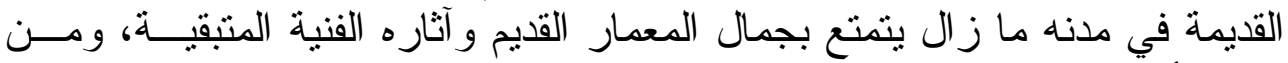

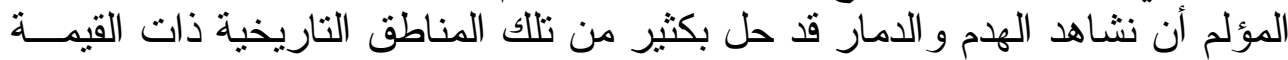

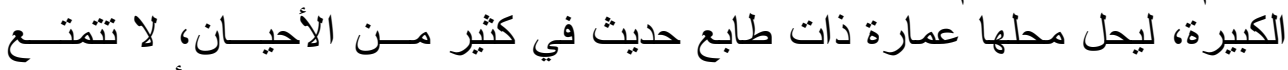

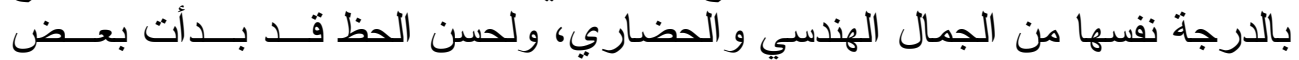

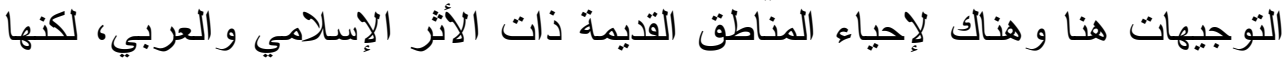

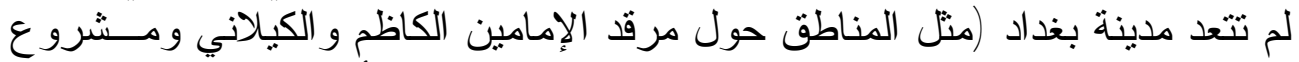

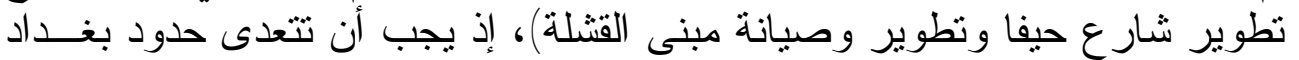

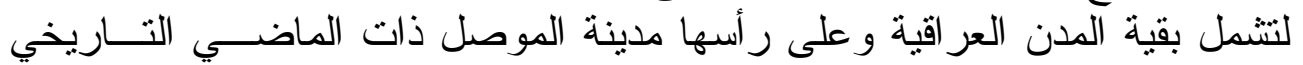

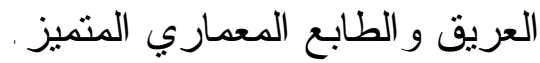

ومع صدور العديد من القو انين و التعليمات التي تتناول هذه المشكلة وخاصة

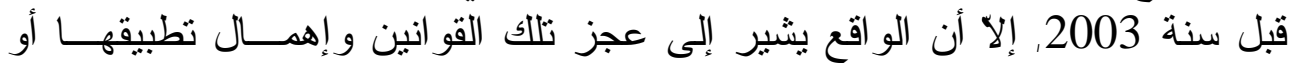

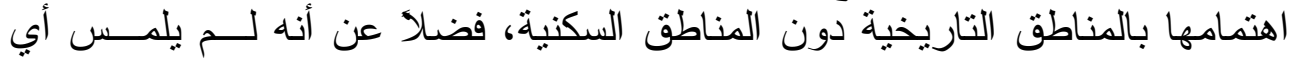

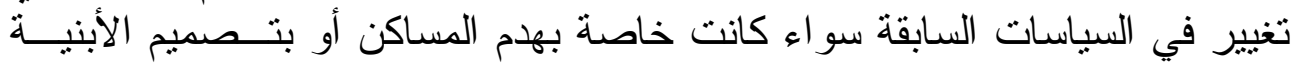

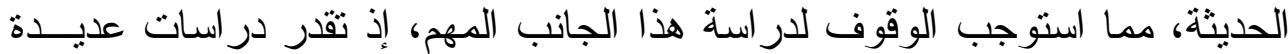

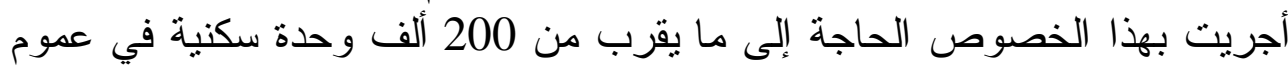
العراق تأتي مدينة بغداد بالمقدمة ينلو ها مدينتا الموصل من ولئ البصرة

\footnotetext{
مشكلة البحث

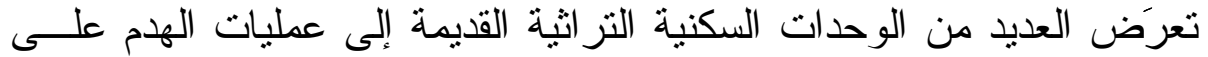

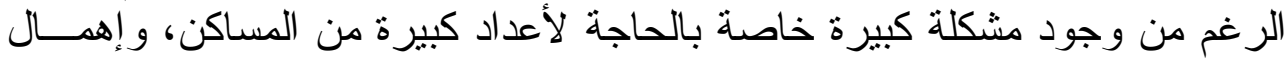

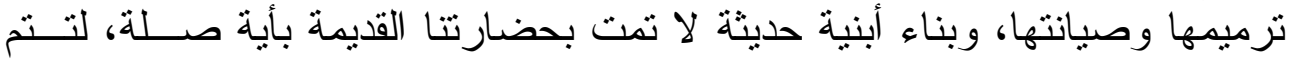

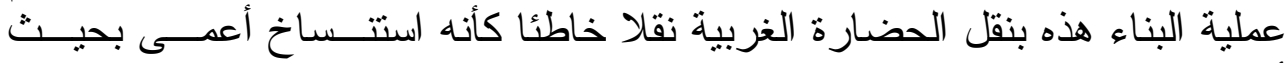

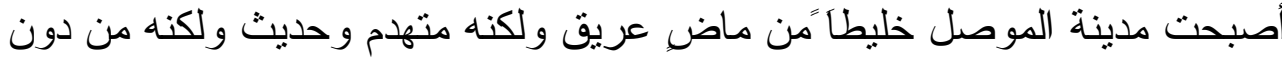


قيمة تز اثية، إضافة إلى تفاقم مشكلة السكن و امتذادها لأكثر من خمسة عقود مــن

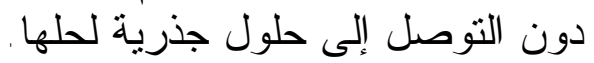

فرضبة البحث

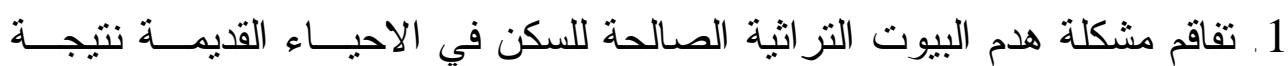

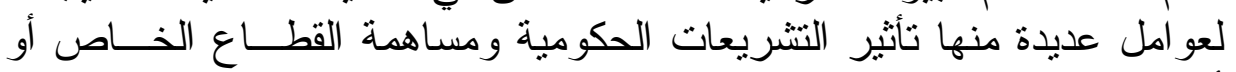

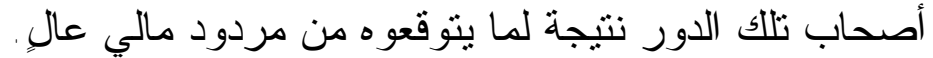

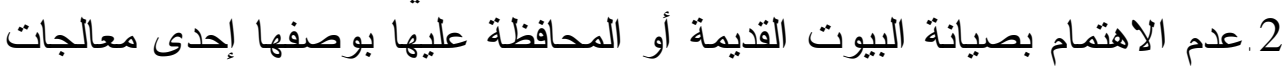

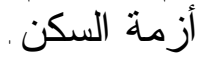

قلة البحوث التي تتتاول مشكلة الإسكان في مدينة الموصل وتوجيه الانظــار أهمية البحث

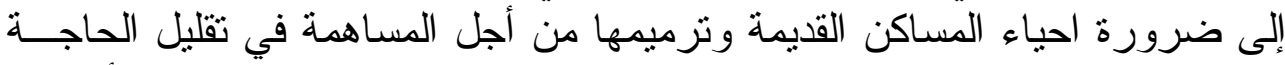

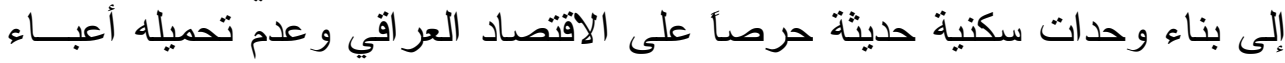

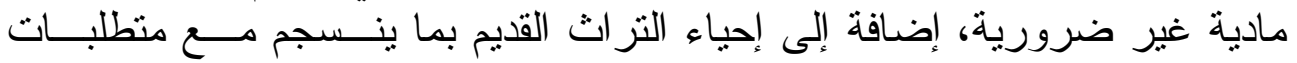

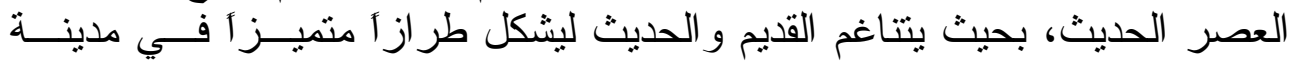

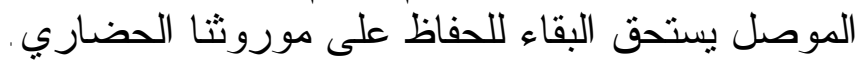

حث الجهات المعنية وخاصة الحكومية على اتخاذ وتطبيق القرار ات التي من

\section{هدف البحث}

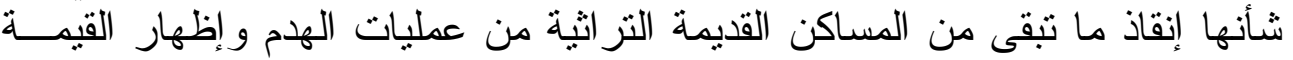

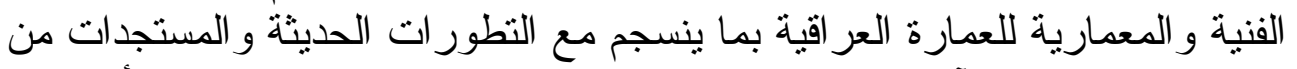

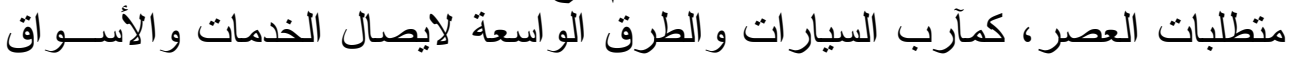

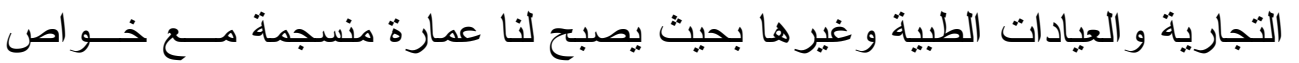

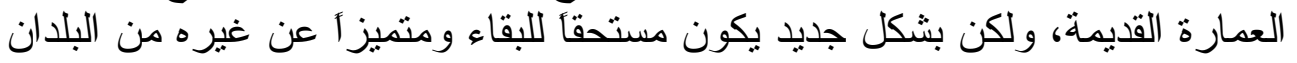

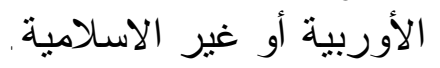

إعتمد البحث الأسلوب الوصفي في تحقيق أهدافه من خلال إجراء المقابلات

\section{منهجية البحث}

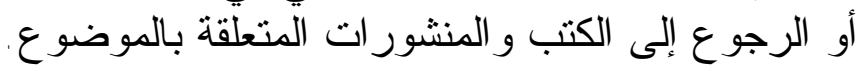

أولاً - الأصول المبدئية المستعملة للمحافظة على التراث

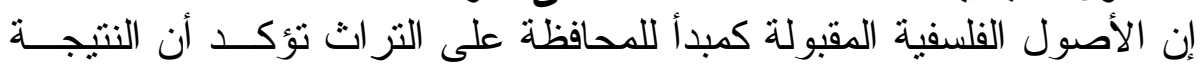

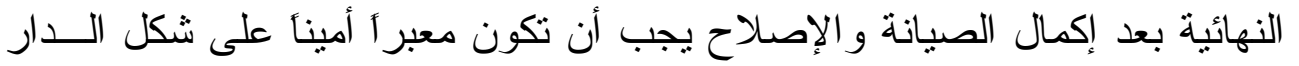

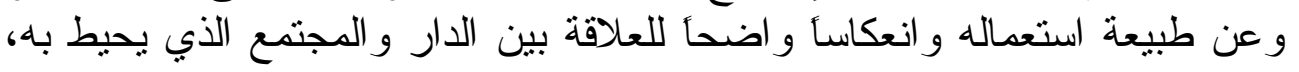


بحيث لا يخفي طابعه القديم و الثكل الأساسي لله و الزمن الذي بني أثناؤه. إن هذا لا لا لإلي

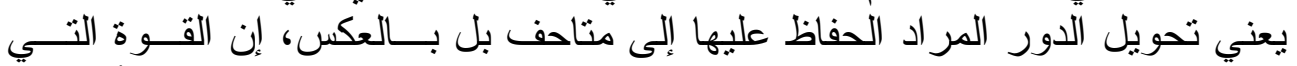

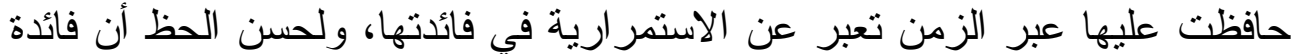

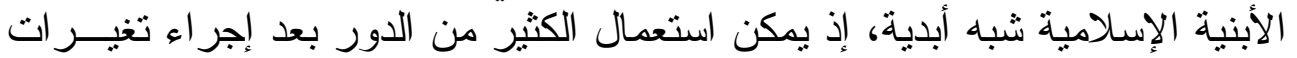

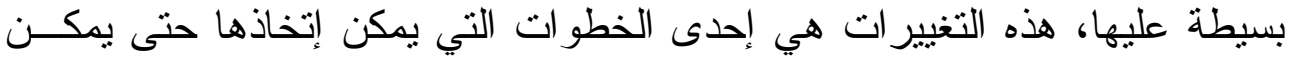

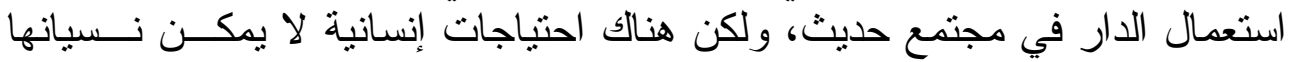

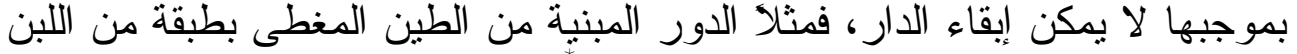

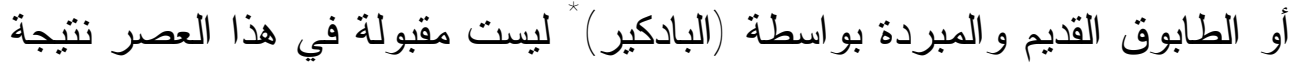
لتطور أجزة التبريد الحديثة.

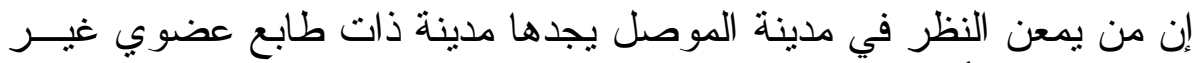

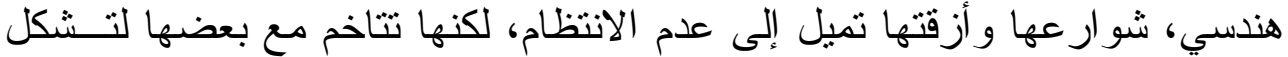

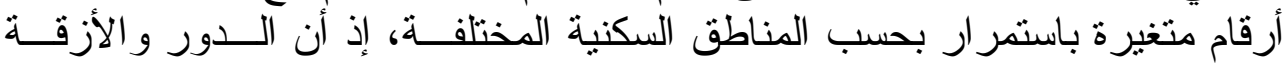

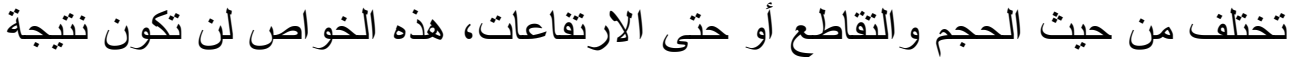

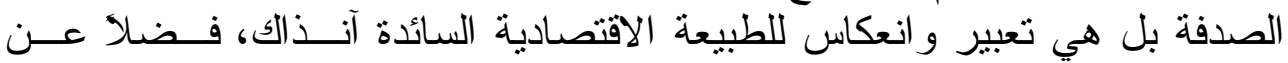

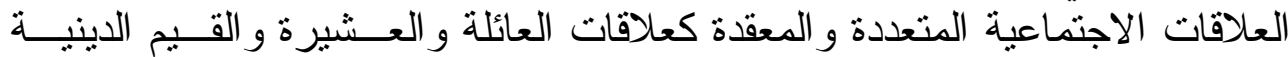

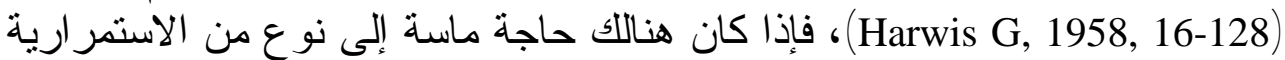

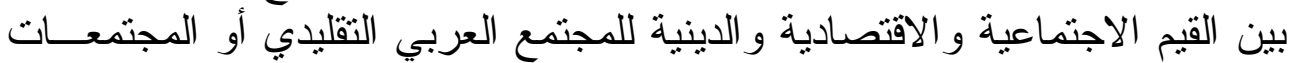

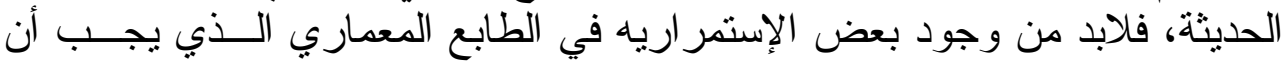

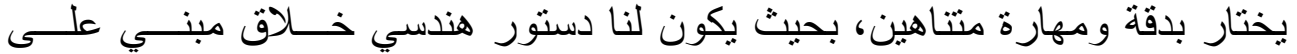

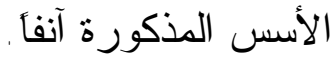

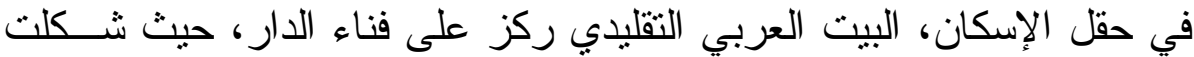

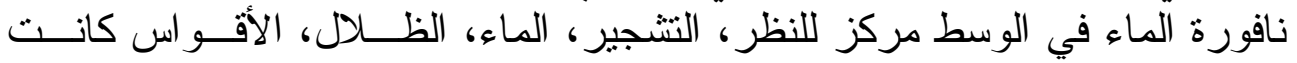

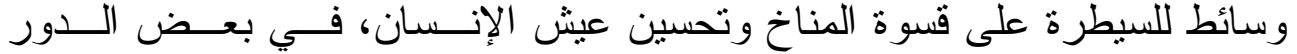

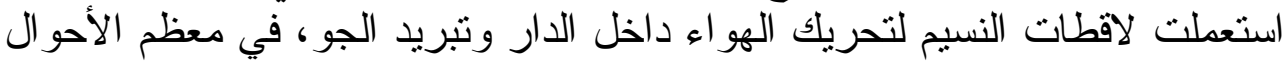

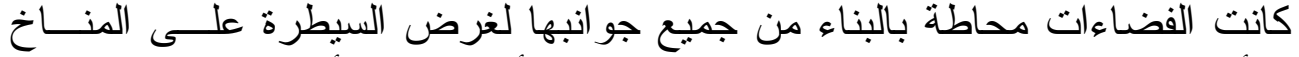

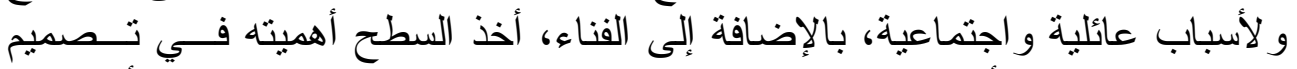

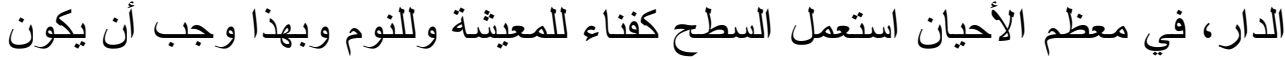

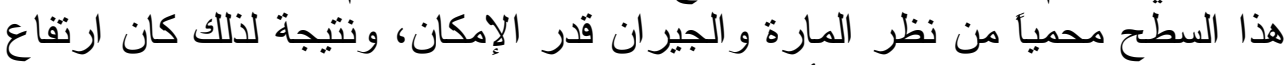

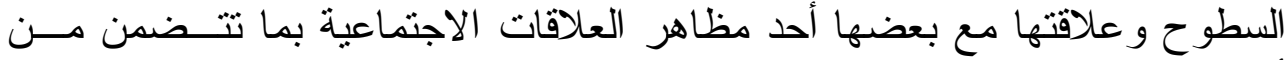

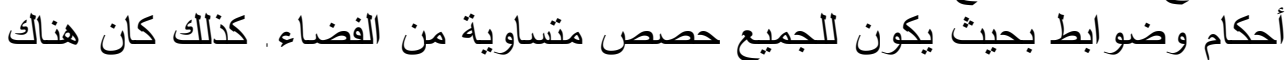
سمتان رئيستان تميز ان البيت العربي الموصلي القديم، ويعبران تعبير أ خارجياً جلياً

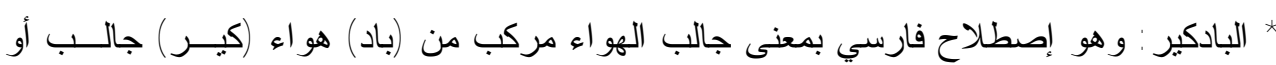

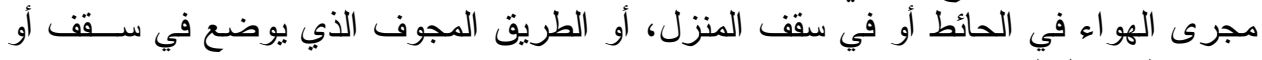
في وسط حائط الحجرة 


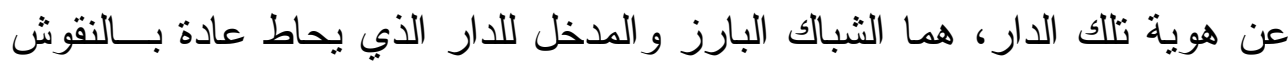

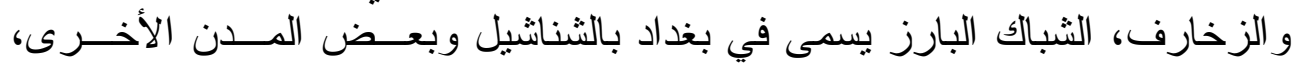

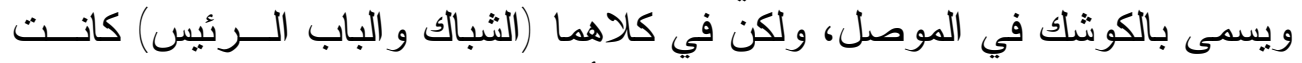

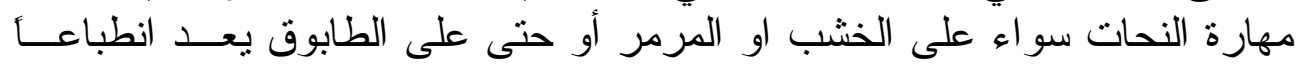

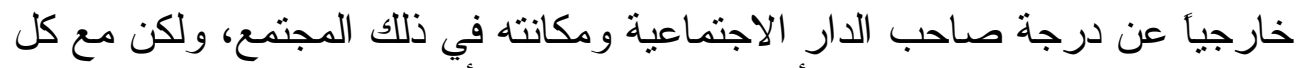

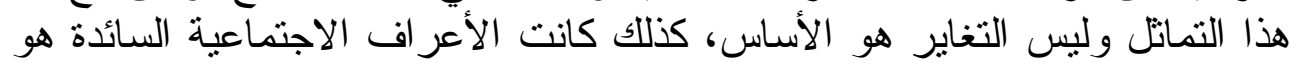

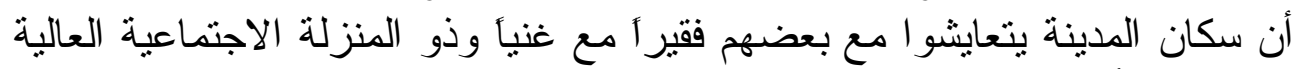

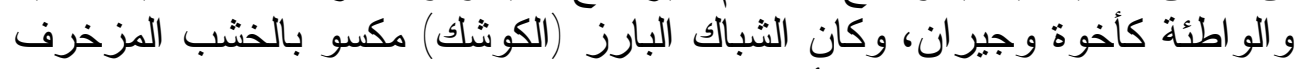

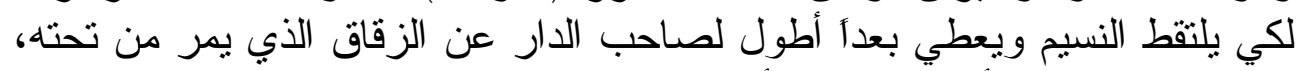

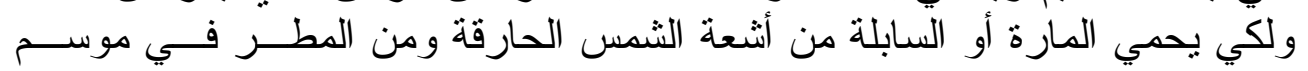

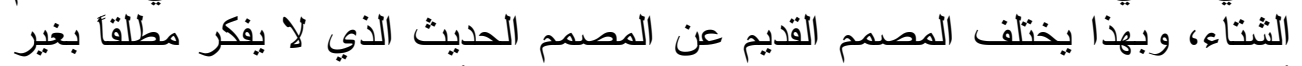

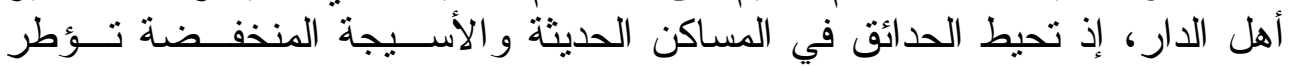

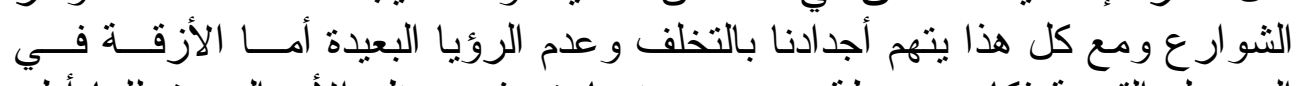

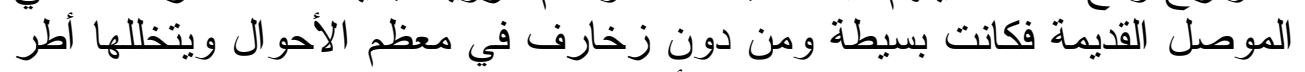

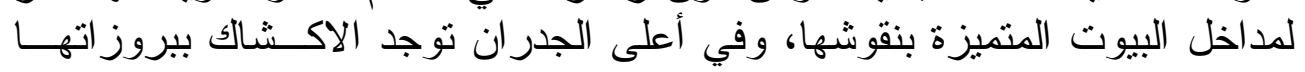

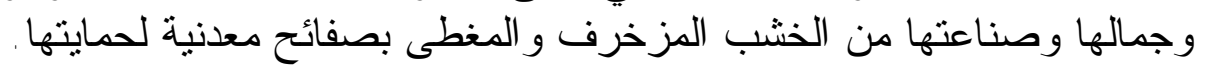

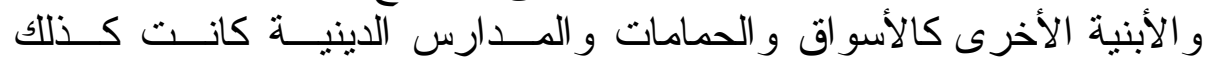

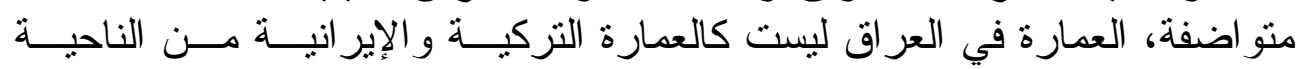

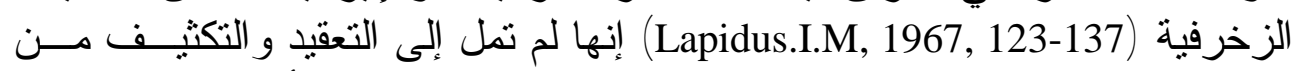

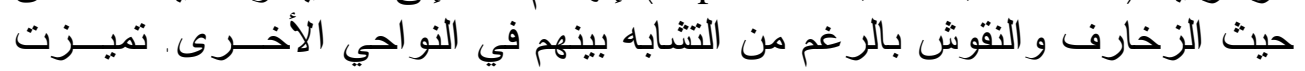

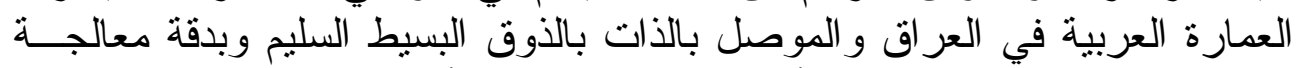

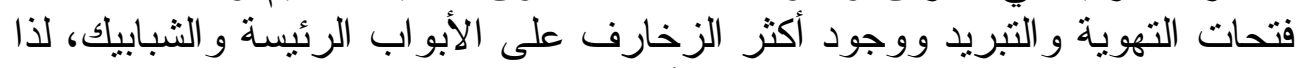

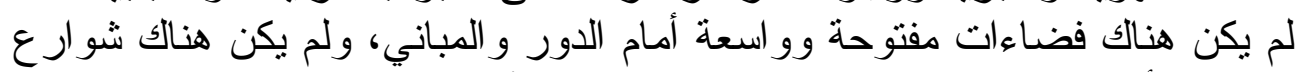

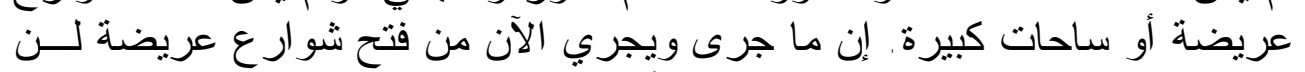

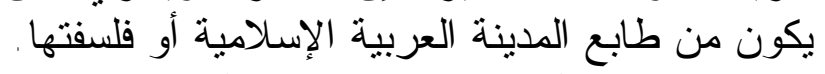

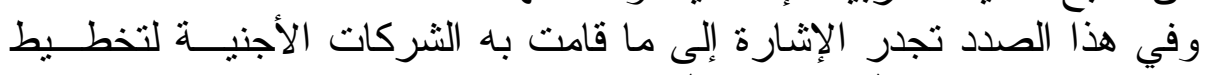

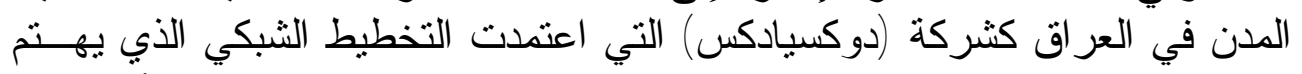

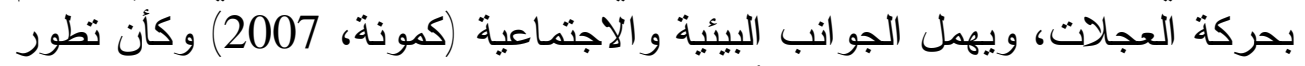

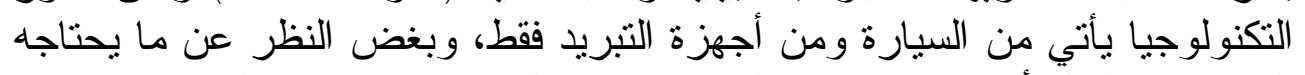

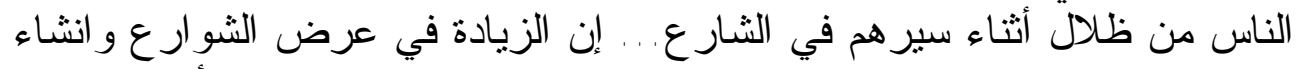

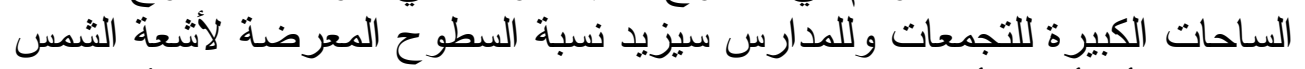

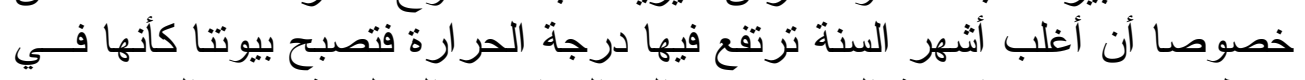

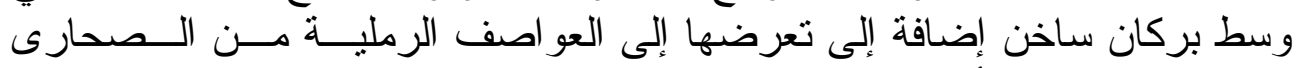

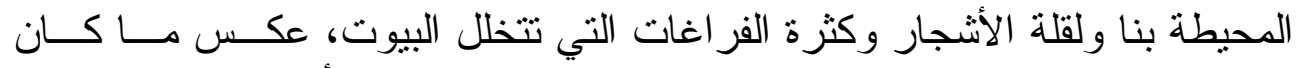

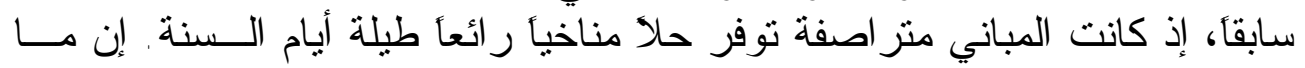

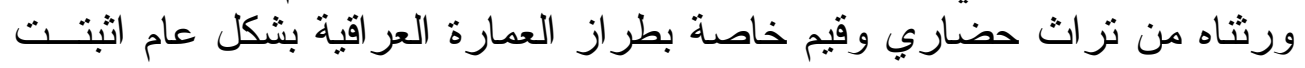


صحتها وملاءمتها لظروفنا المناخية القاسية، لذا علينا أن نحترم قو اعدها ونعمل بها

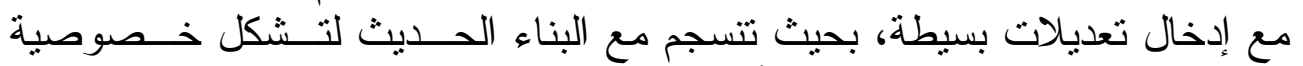

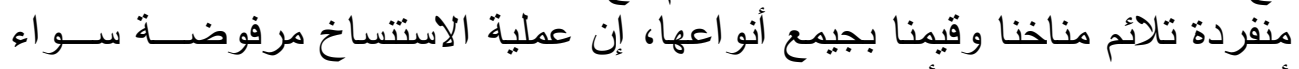

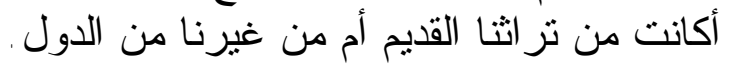

ثانياً - الأسباب المؤدية إلى عملية الهدم المتعد الأداد

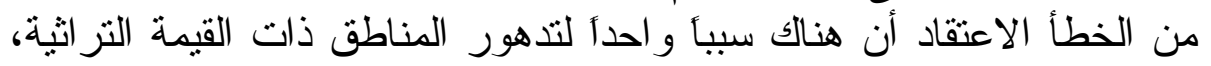

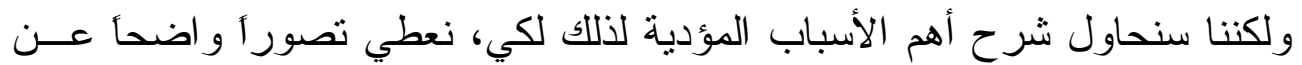

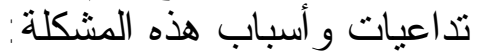

\section{1 إهمال عمليات التصليح و الصيانة}

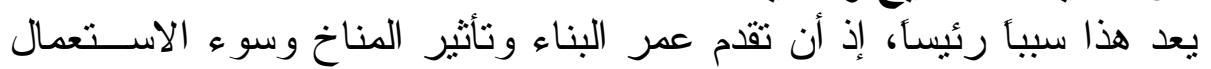

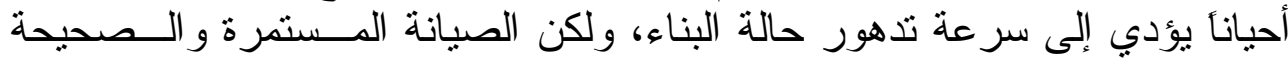

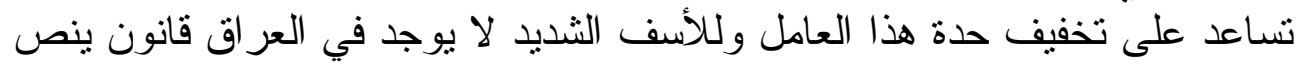
على إدامة وحماية البيوت القديمة ذات القيمة التز اثية.

\section{2. فتح الثوارع ويناء المشاريع الضخمة}

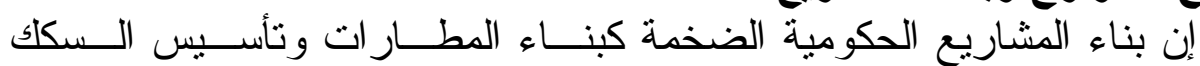

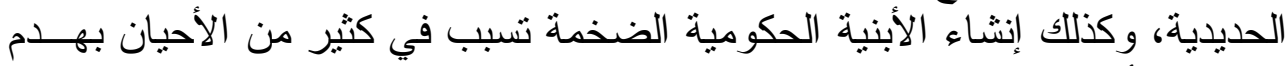

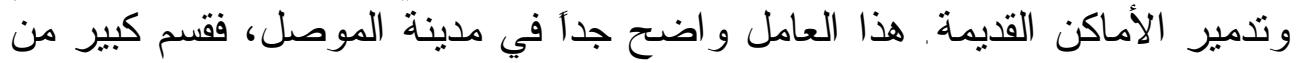

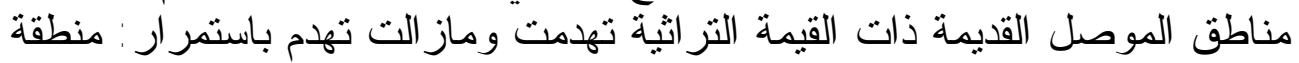

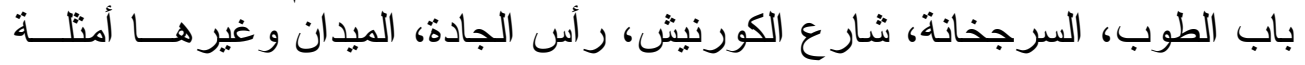

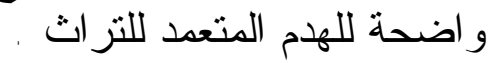

3. هدم الدور و الأبنية القديمة على جاتبي الثارع الجديد

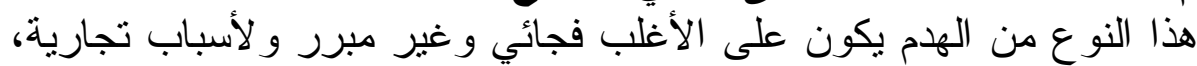

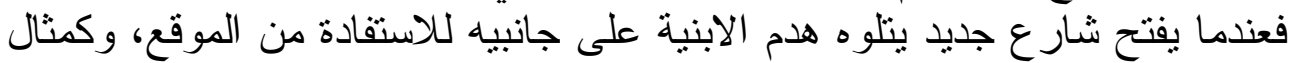

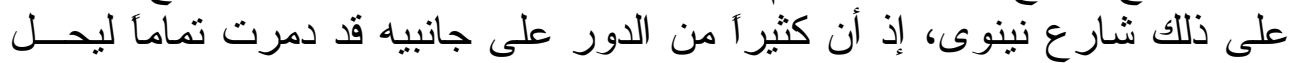

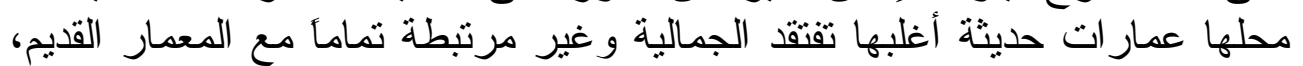

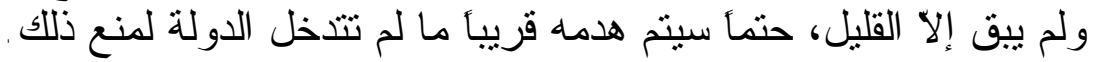

4. فقدان الأبنية القديمة نتيجة المحاولات لاستنساخ العمارة الغربية

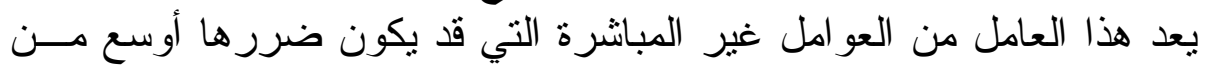

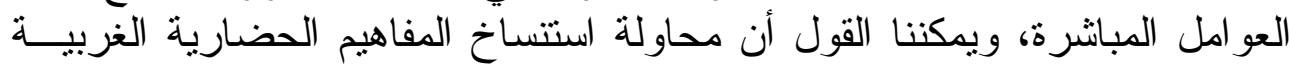

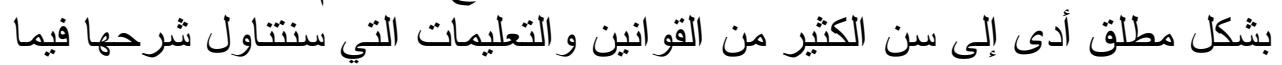


بعد. في الغرب كان هناك يقظة حضارية ورغبة في الحفاظ على القيمة التراثيــــة

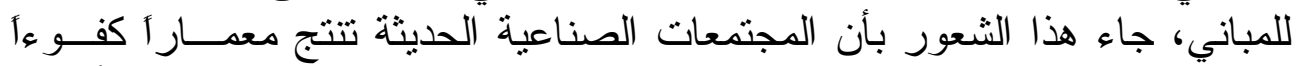

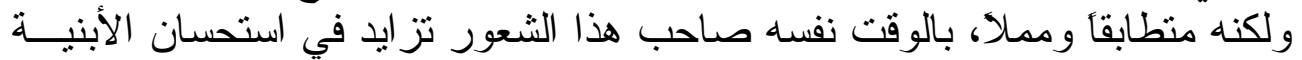

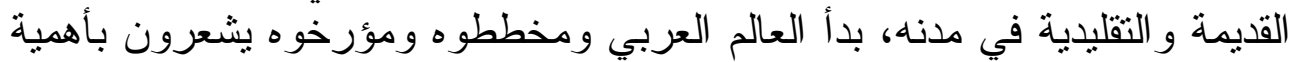

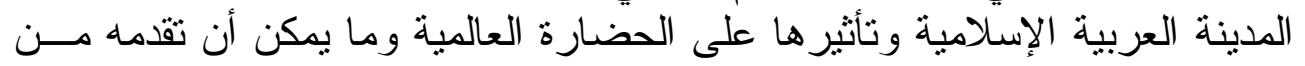

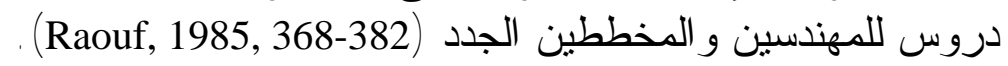

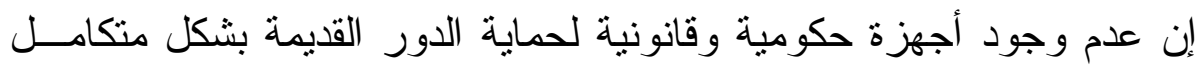

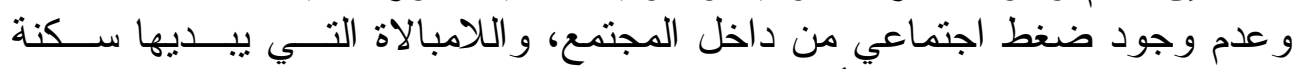

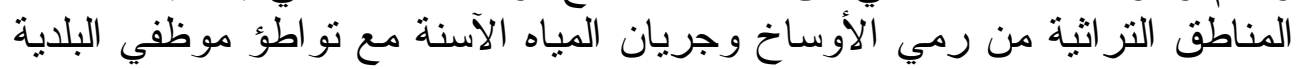

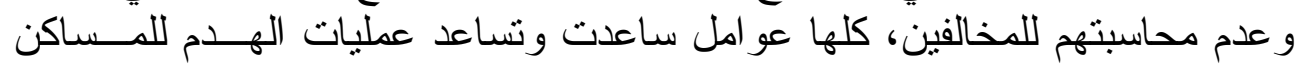

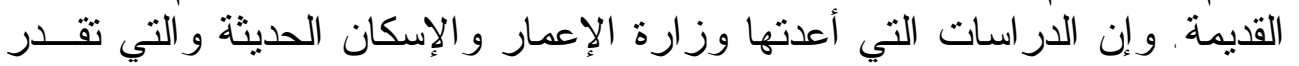

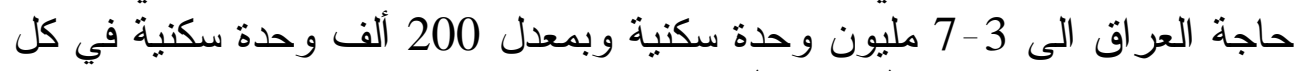

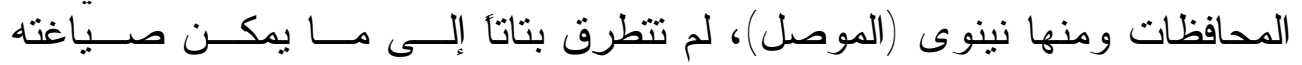

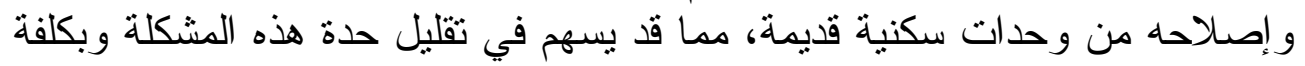

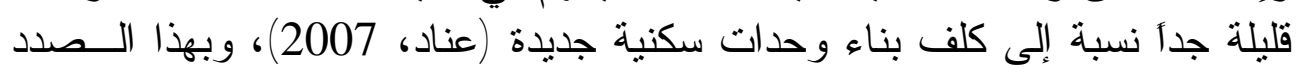

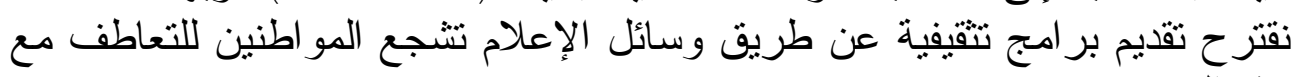
هذه الفكرة.

5. الفقدان نتيجة التلخل غير المرغوب على فضاء الدور ذات القيمة التراثية

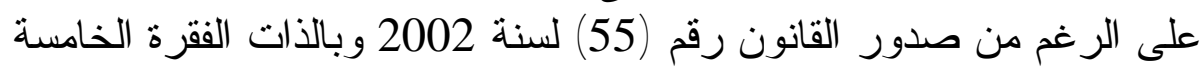

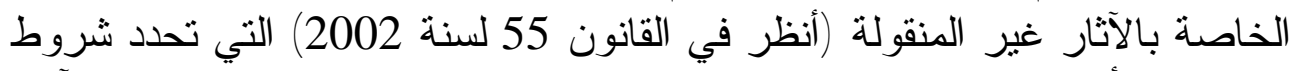

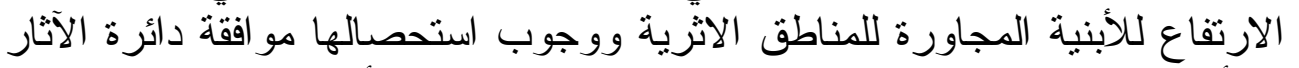

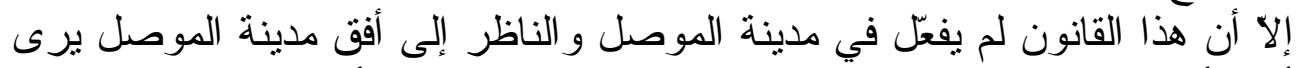

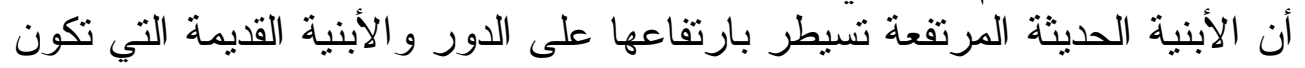

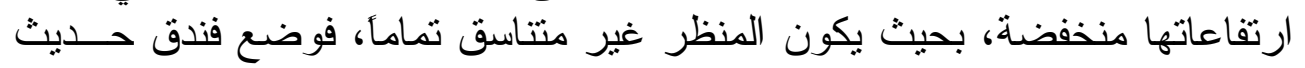

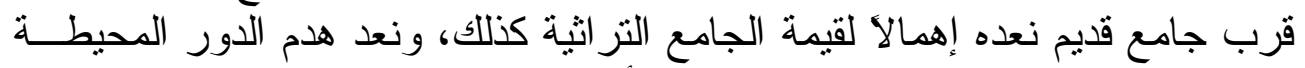

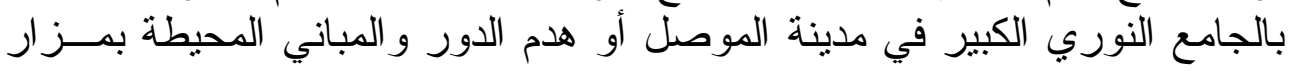

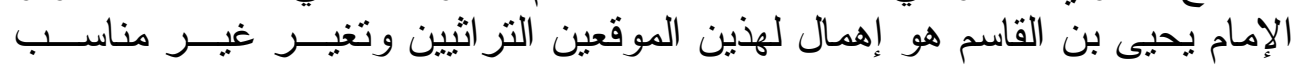

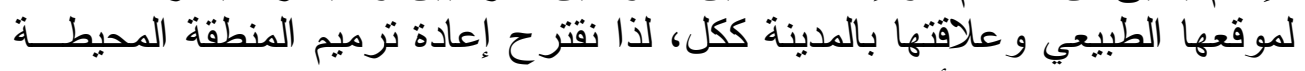

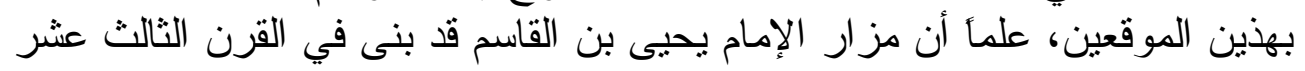

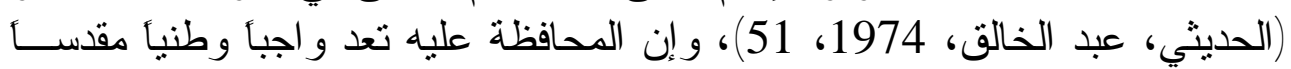

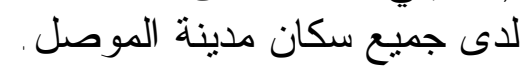

6. الفقدان نتيجة الصيانة والتصليح المؤذي للبناية أو البيئة المحيطة بها 


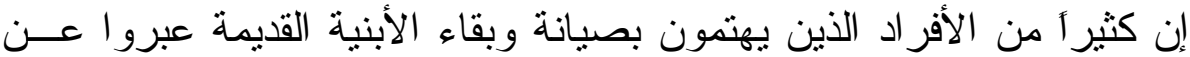

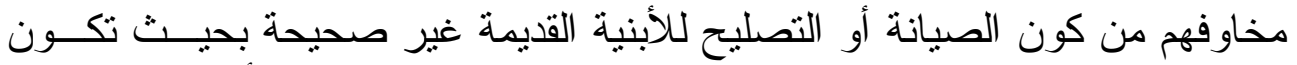

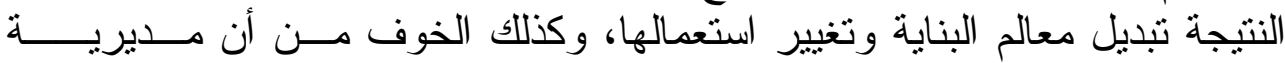

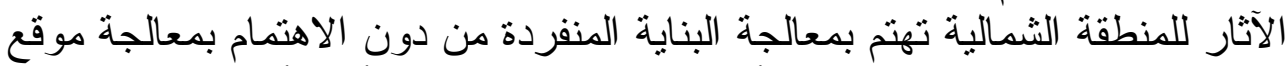

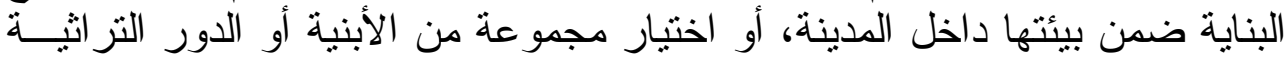

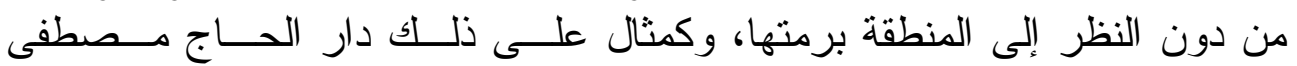

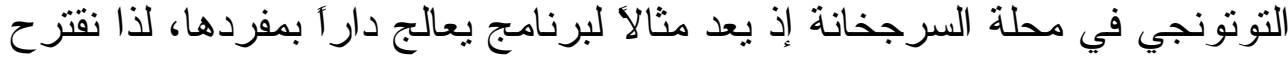

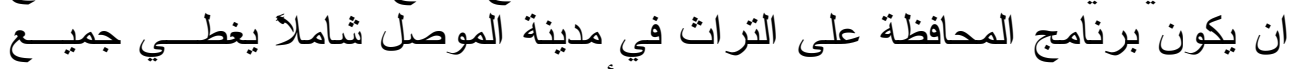

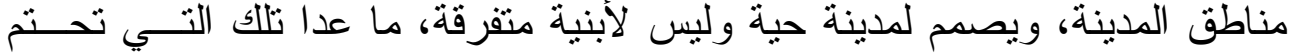
الضرورة معالجتها بصورة فردية.

7. الفقدان نتيجة للسرقة و التخريب

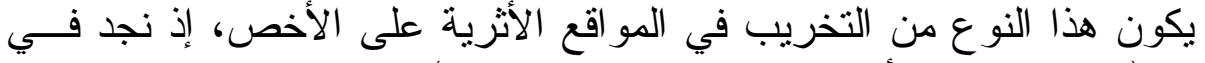

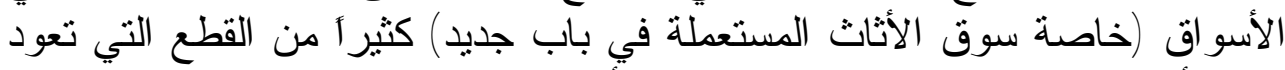

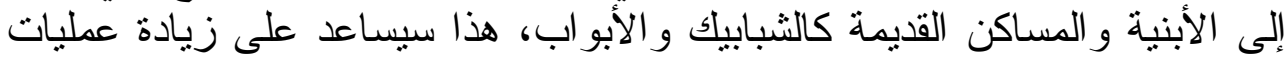

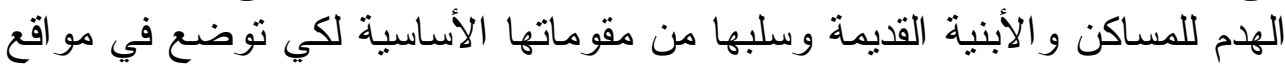
حديثة لا تتتاسب معها.

8. الفقدان نتيجة القوانين و التعليمات

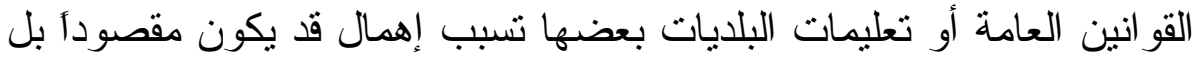

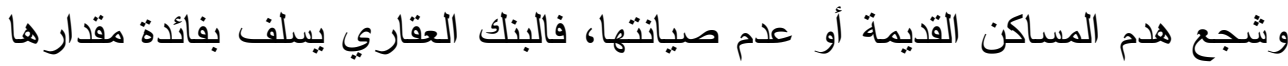

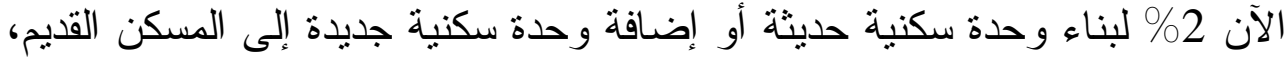

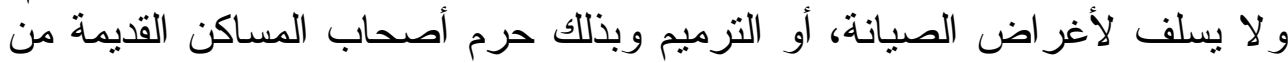

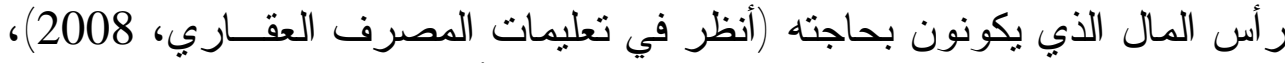

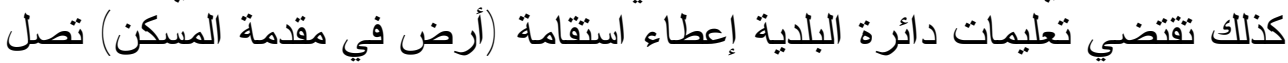

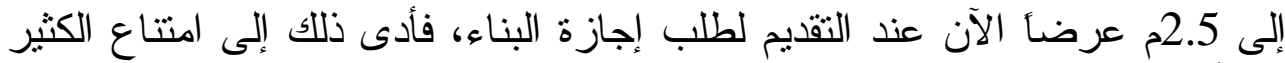

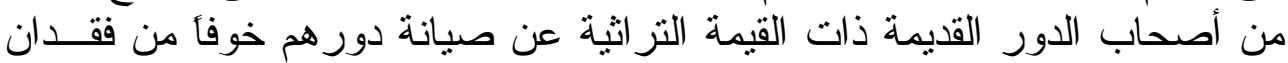

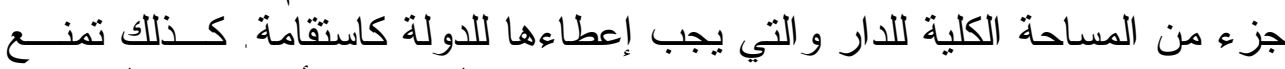

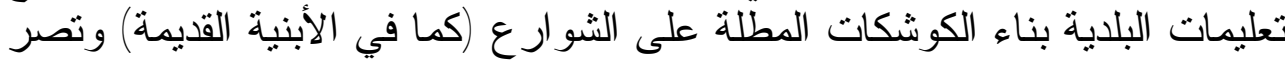

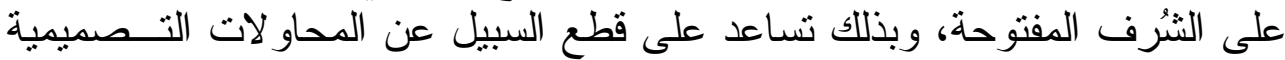

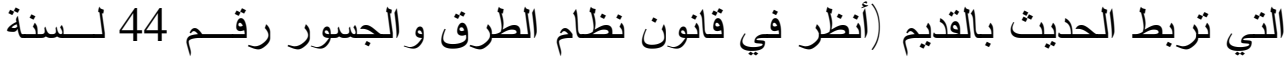
1935 (المعدل).

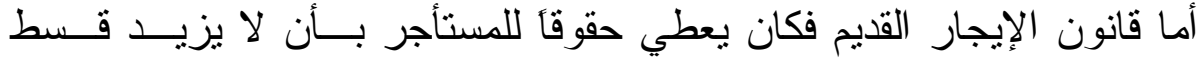

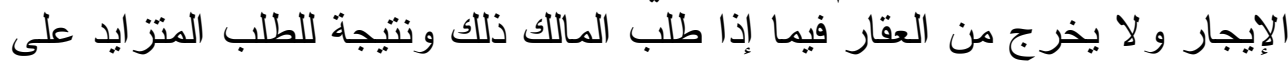

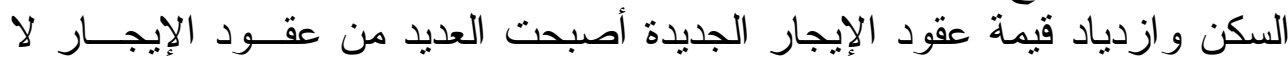




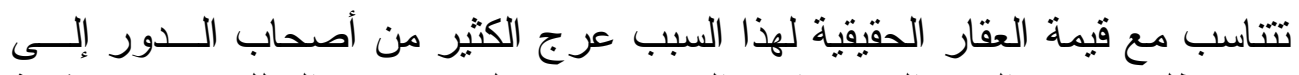

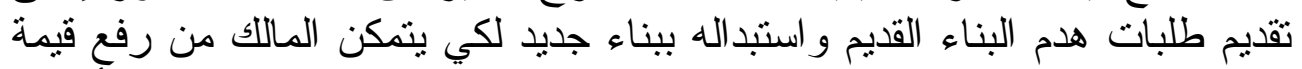

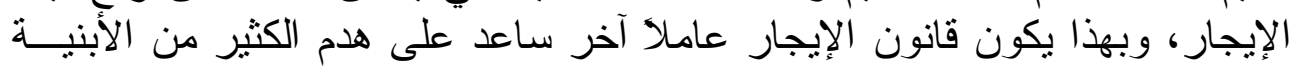

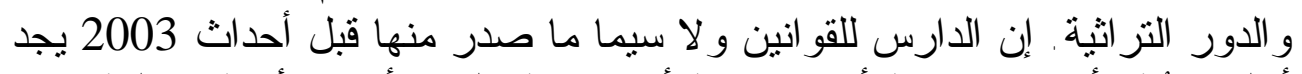

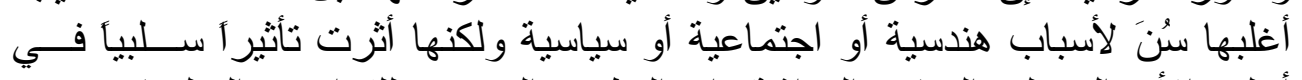

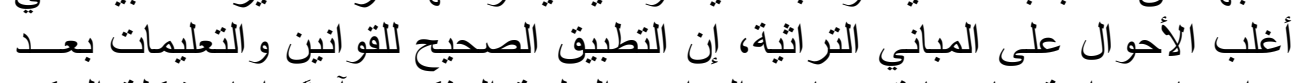

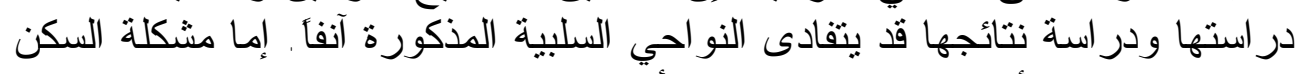

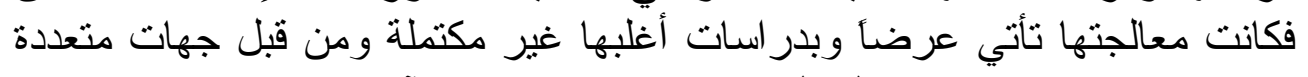

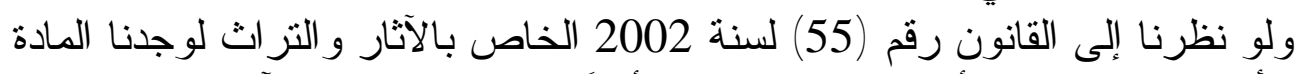

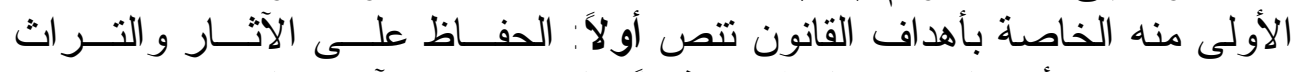

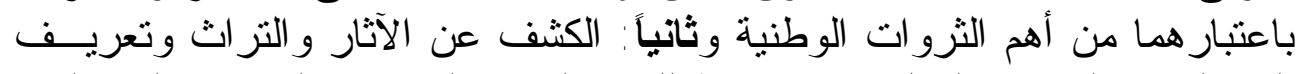

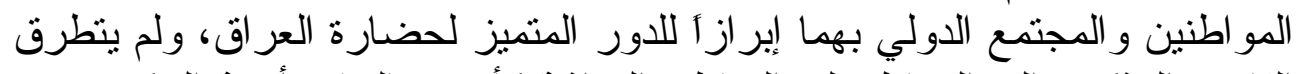
القانون المذكور إلى الحفاظً على المناطق التراثية كأحد معالجات أزمة السكن.

\section{ثالثاً - لماذا يجب أن نتحرك الآن؟}

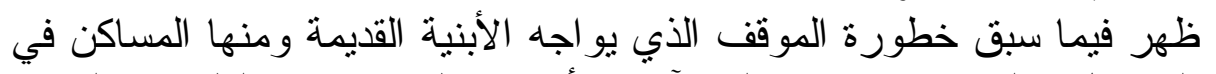

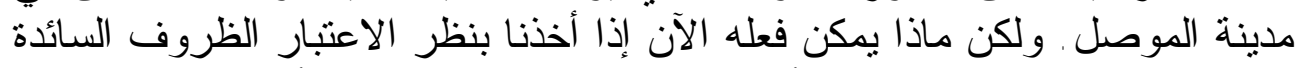

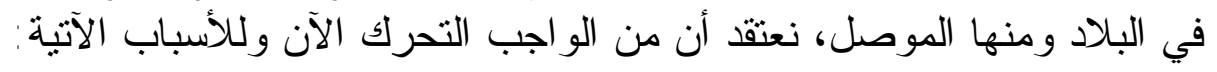

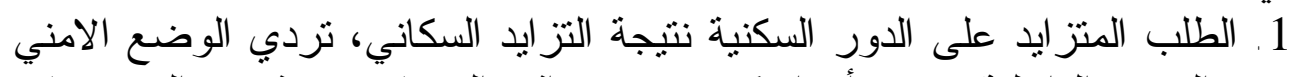

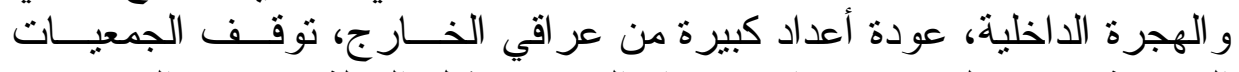

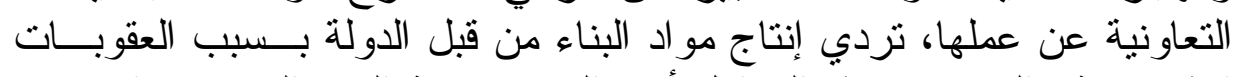

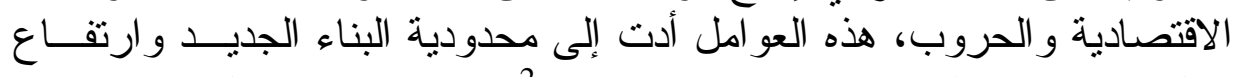

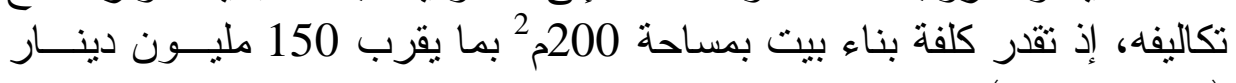

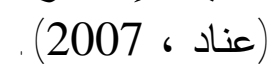

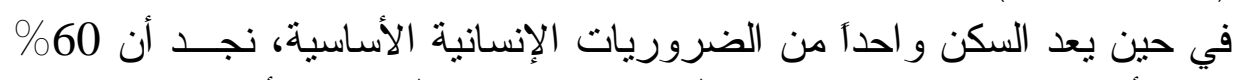

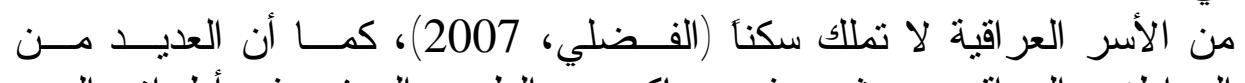

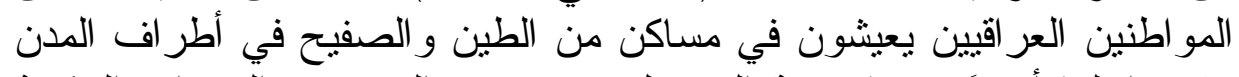

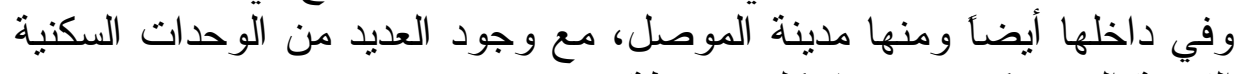

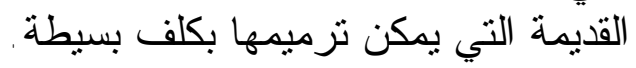

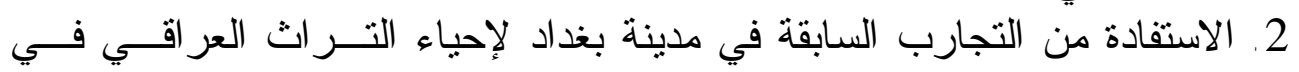

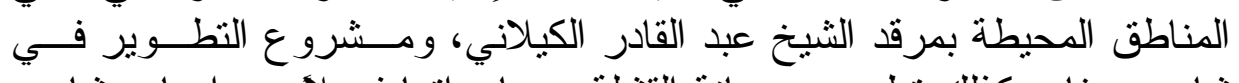

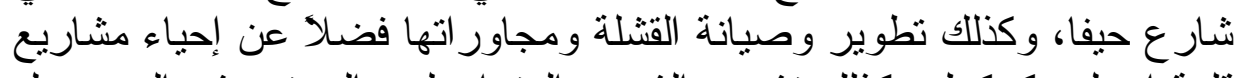

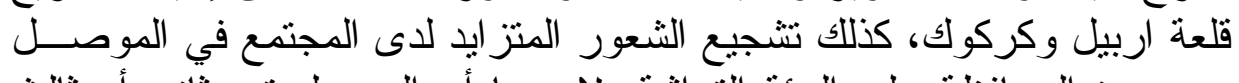
بضرورة المحافظة على البيئة التزر اثثة، لا سيما أن الموصل لإى تعد ثاني أو ثالث 
مدن العر اق من حيث الحجم، من هنا يجب أن تأخذ حصتها من الاهتمام مسن

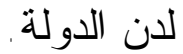

3. إنقاذ ما يمكن إنقاذه من خبر ات في البناء القديم، فالكل بعلم أن تقنيــات البنـــاء

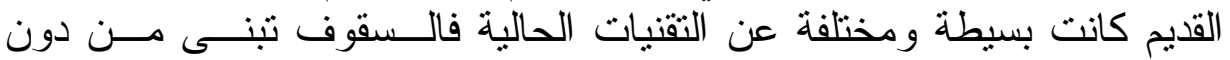

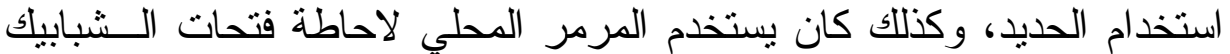

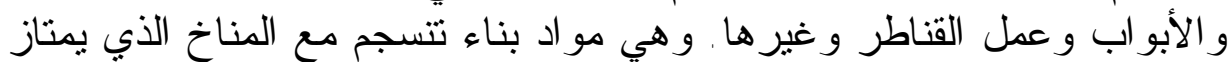

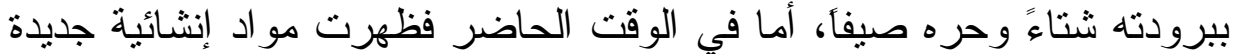

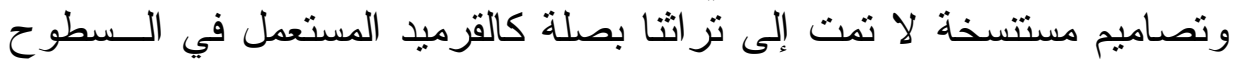

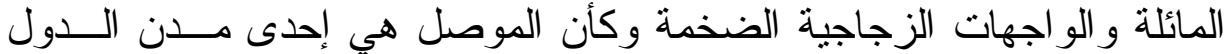

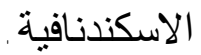

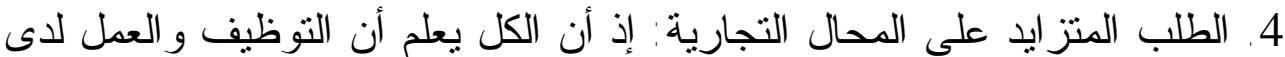

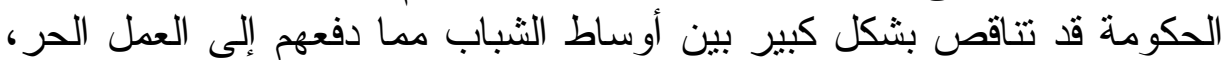

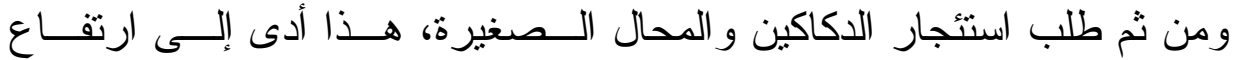

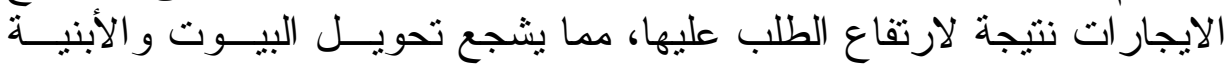

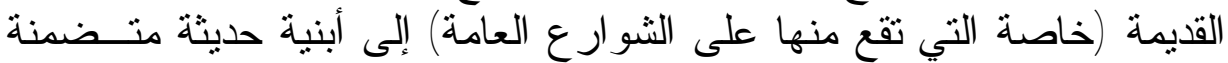

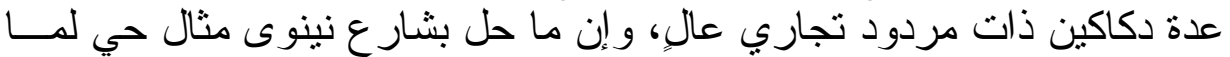

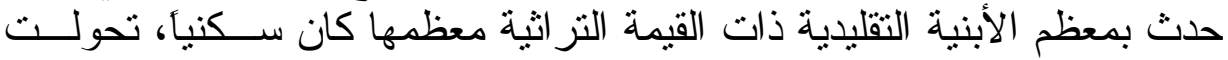

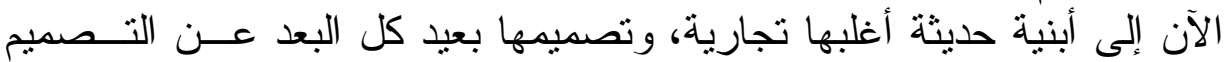

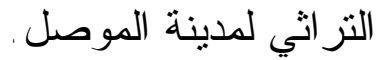

إن ما ذكر آنفأ يجعلنا نقتز ح أن تسار ع الدولة بتفعيل قانون رقم (55) لـسنة

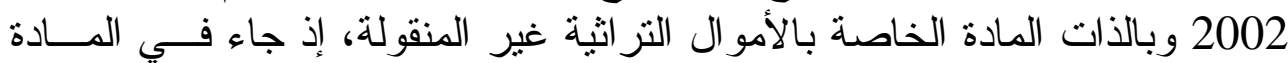

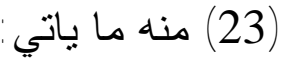

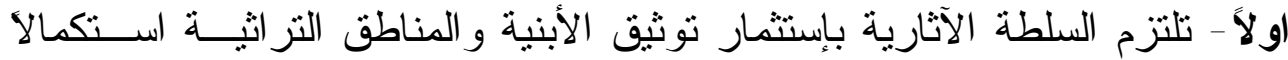

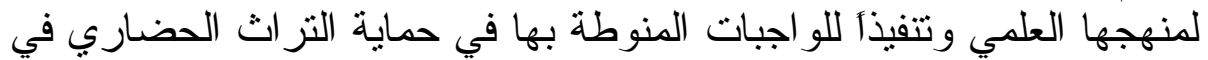

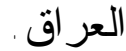

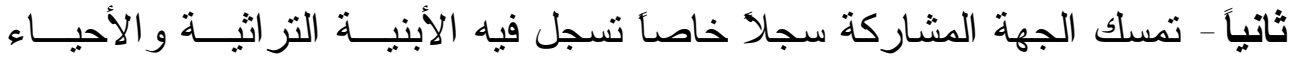

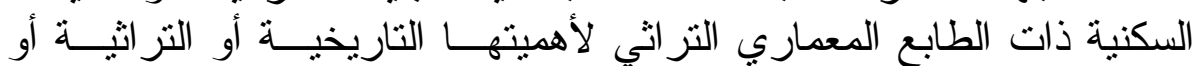

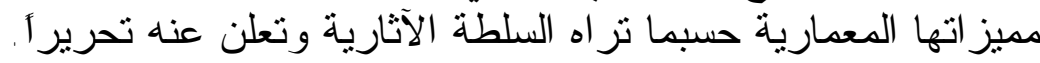

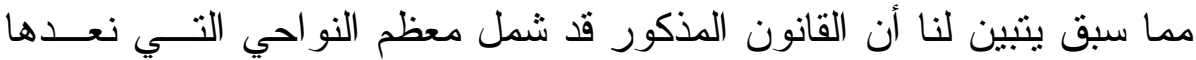

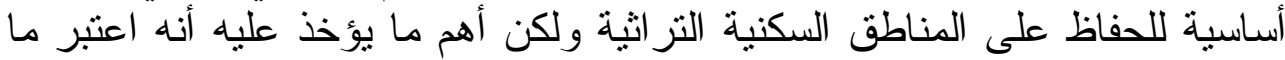

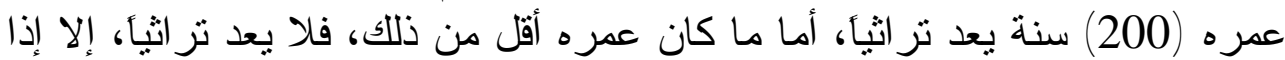

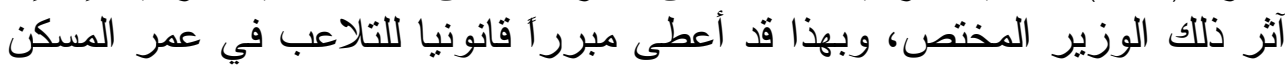


أو المباني، فكثير من المساكن القديمة ذات الطابع التراثي العربي و الإسلامي فـي مدينة الموصل قد بنيت بعد هذان التبن التاريخ.

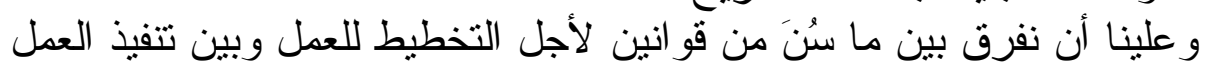

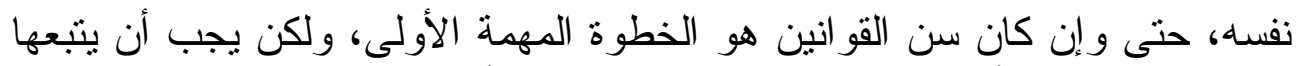

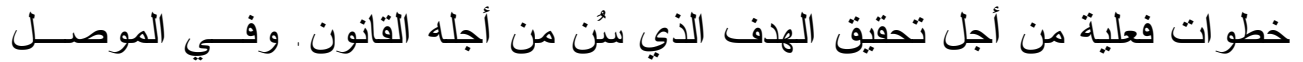

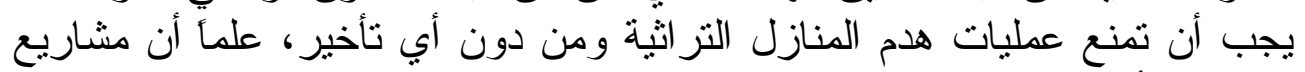

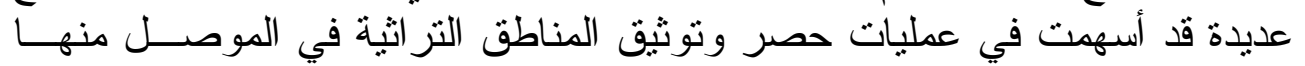

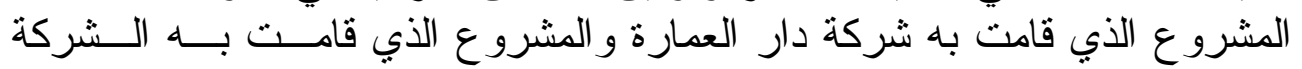

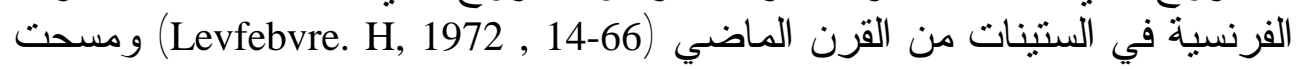

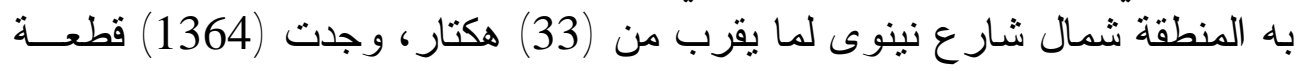

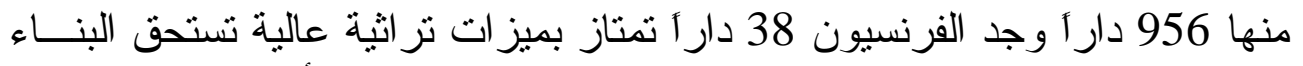

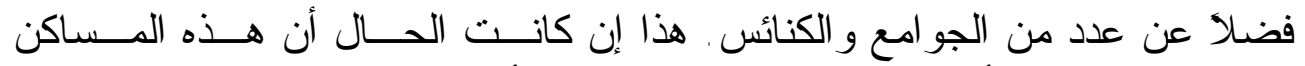

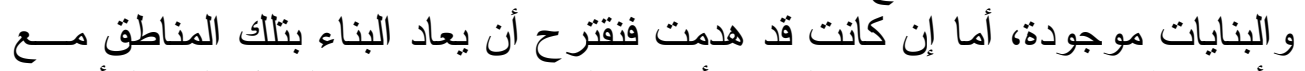

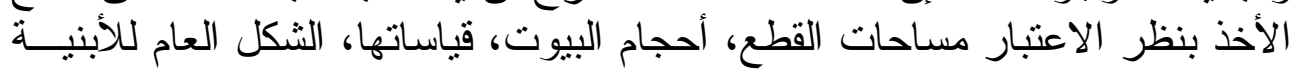

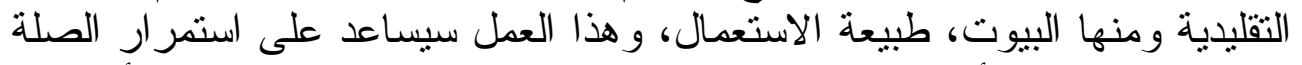

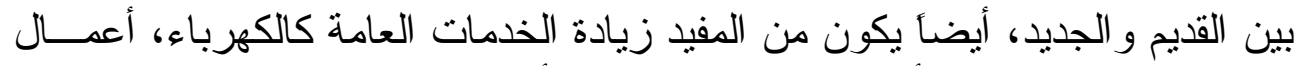

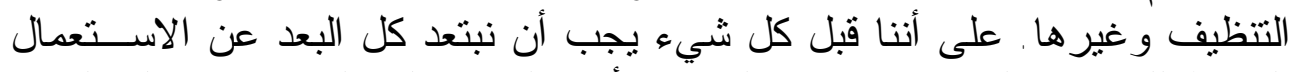

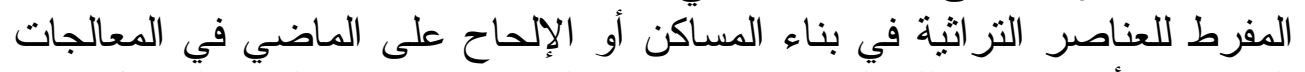

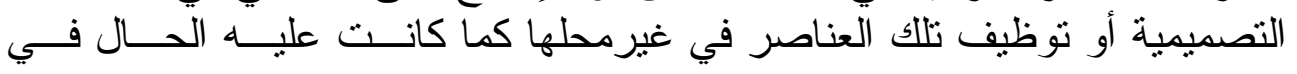
القصور الرئاسية بحسبما اتفق عليه كثير من النقاد (السلطاني، 2007).

\section{رابعاً - أهم المناطق التي تحتاج إلى عمليات الترميم و المعالجة

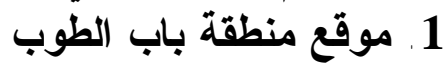

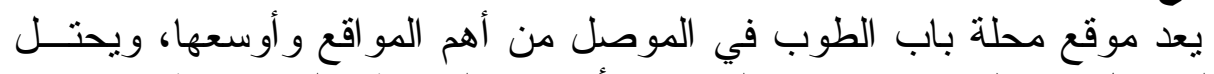

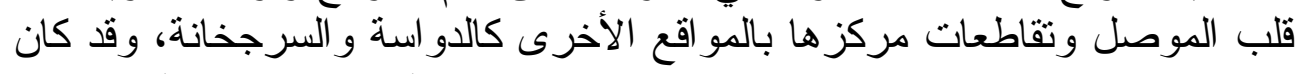

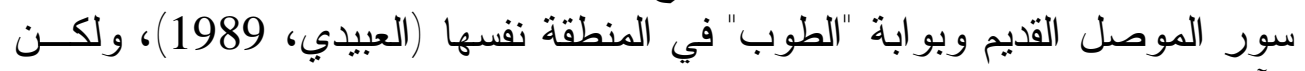

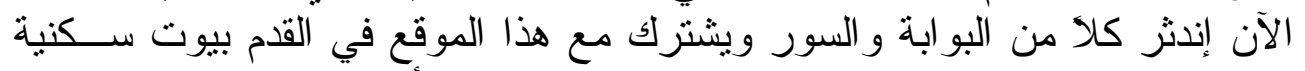

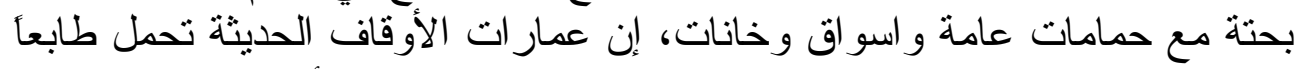

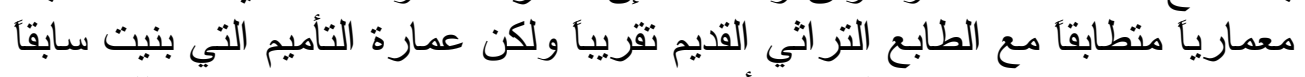

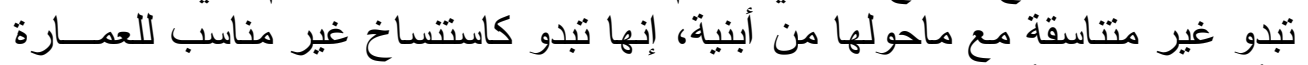

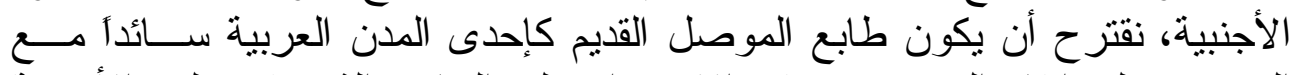

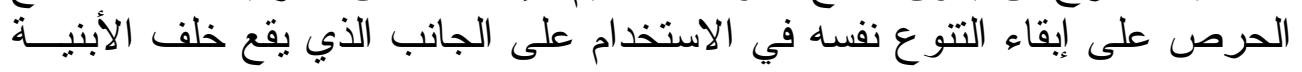

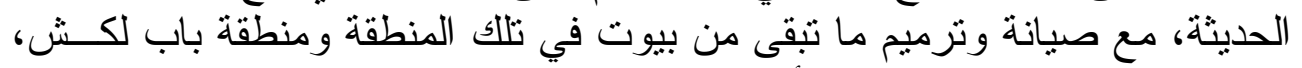

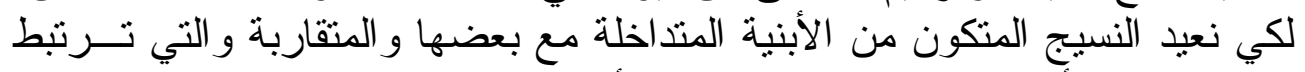

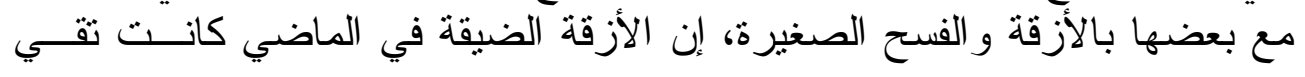




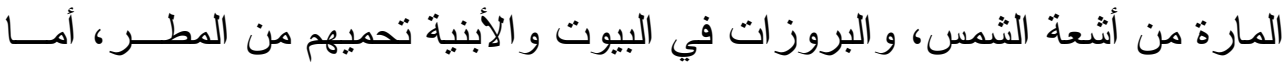

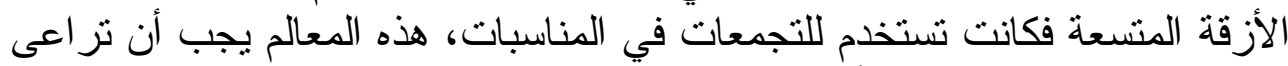

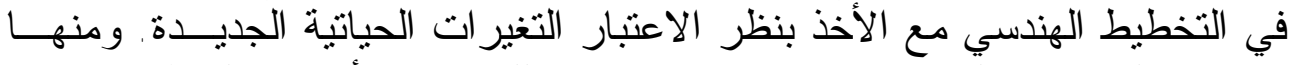

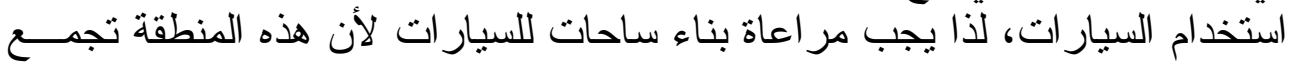
بين المباني التجارية و الوحدات السكنية.

\section{20 20 موقع منطقة السرجخانة}

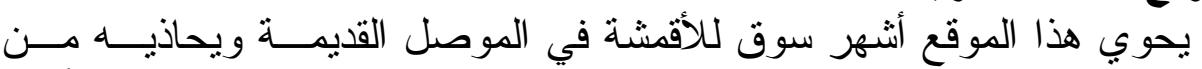

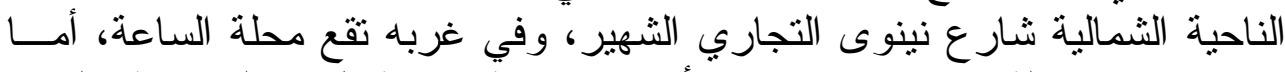

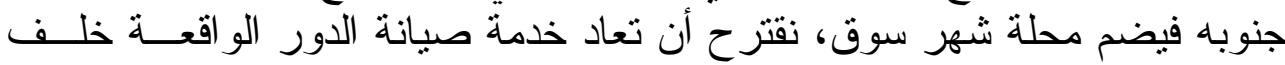

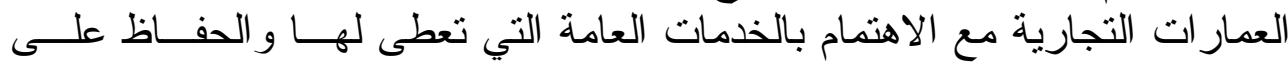

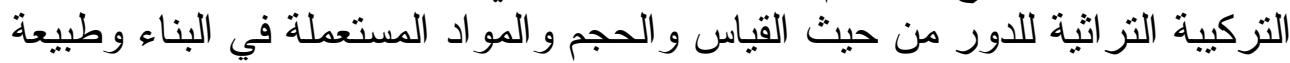

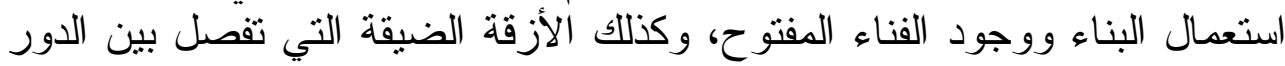

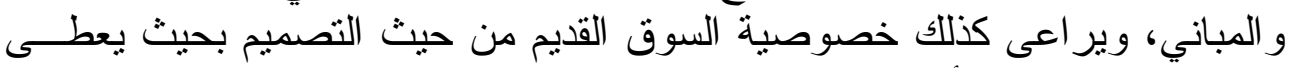
حرمة متميزة للنساء أثناء التسوق.

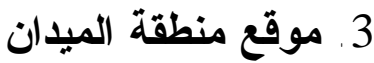

يقع هذا الموقع شمال شار ع نينوى ويحاذي نهر دجلة من المنطقة الـشرقية

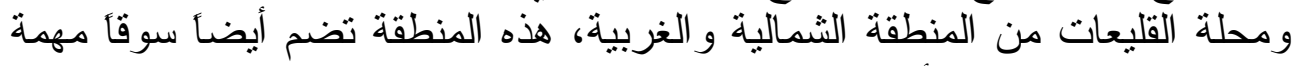

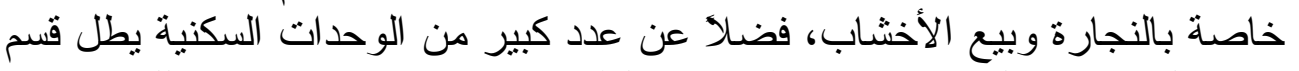

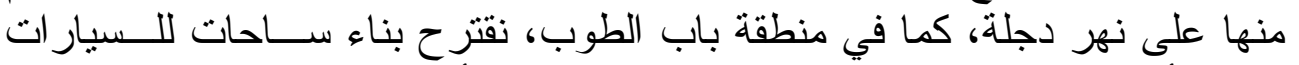

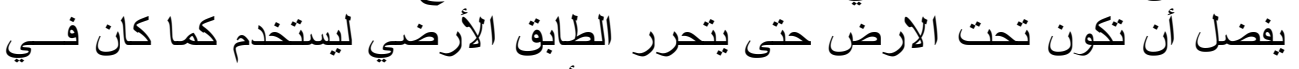

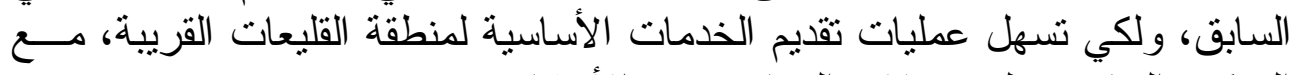
التزكيز الخاص على نلى محلات النجارة وبيع الأخشاب.

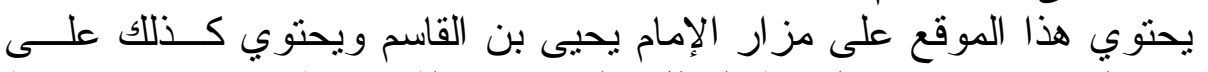

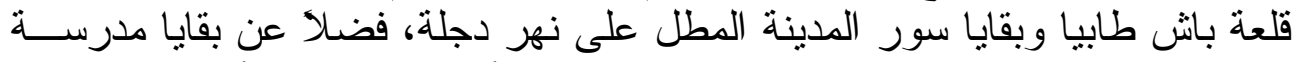

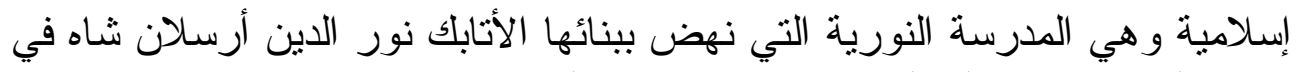

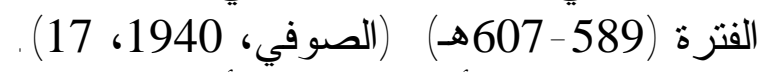

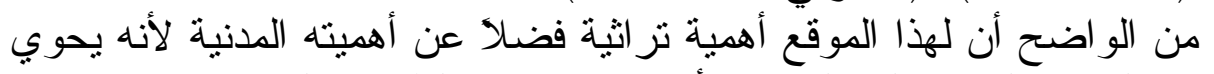

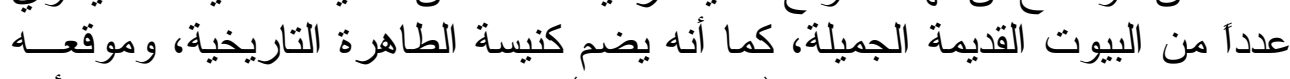

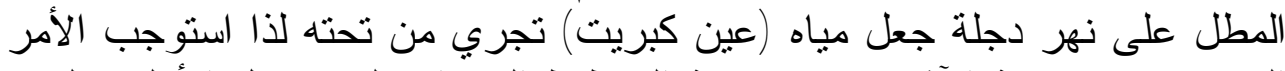

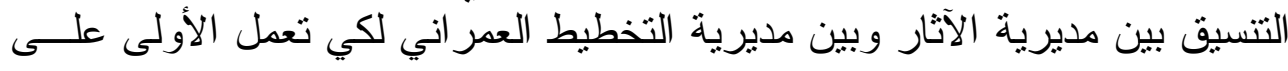




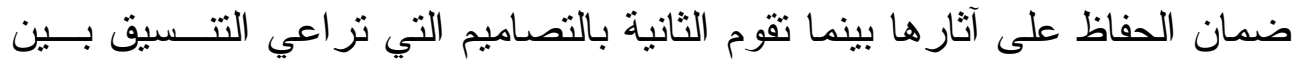

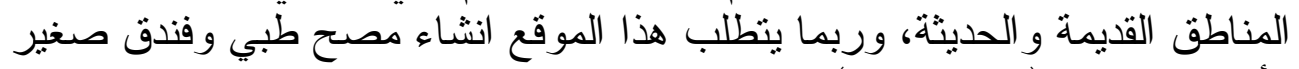

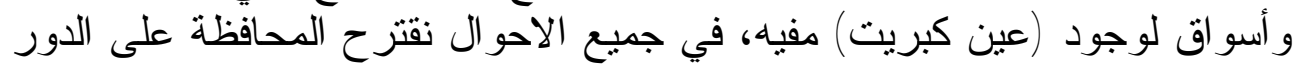

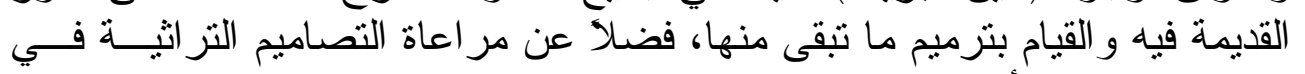
حالة إنشاء بيوت أو مبان جديدة.

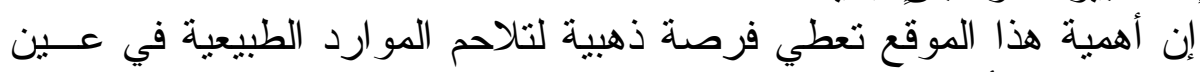

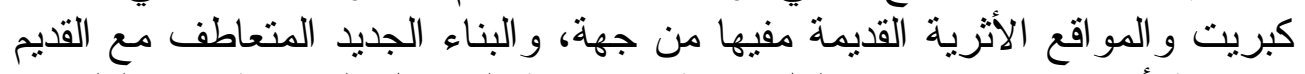

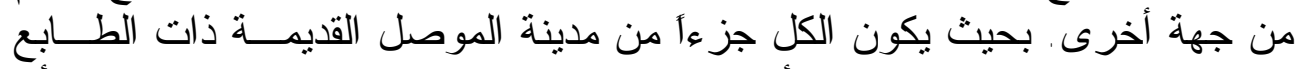

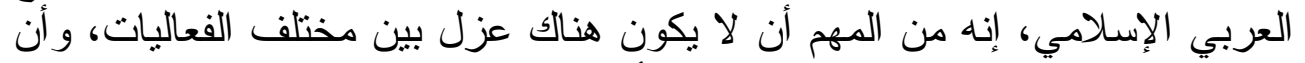
لا تعمل دو ائر الآثار و السياحة، المحافظة أو البلديات بمعزل عن بعض لانها.

\section{الاستنتاجات و التوصيات}

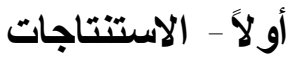

1. هناك عدد من القو انين و التعليمات التي تتتاول موضو عات العات العمارة العر اقية القديمة

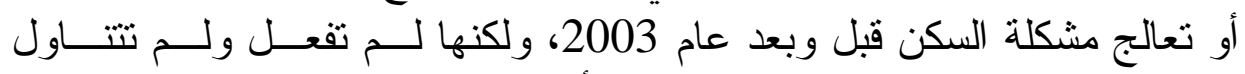

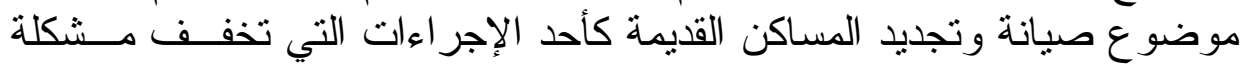

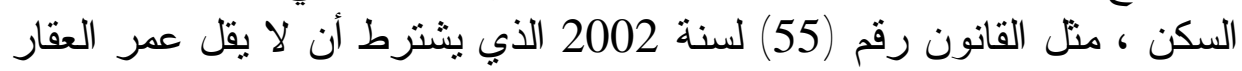

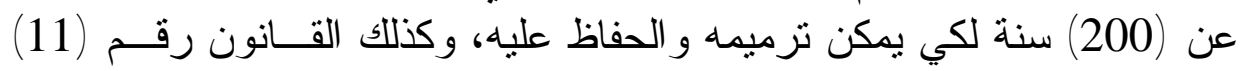

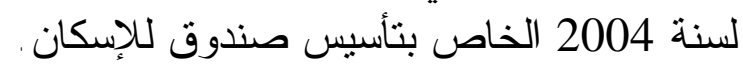

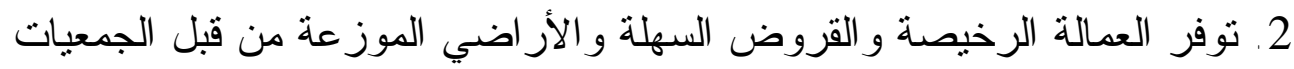

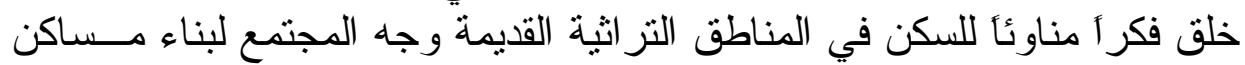

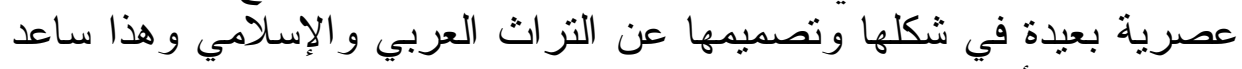

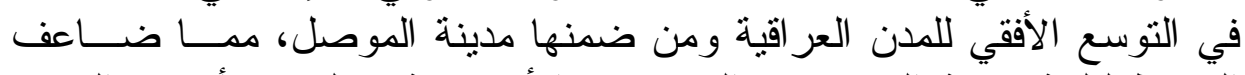

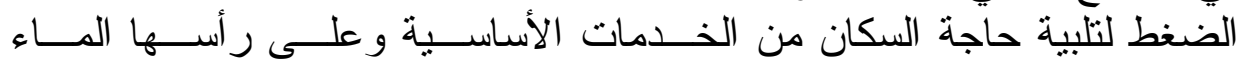

$$
\text { و الكهرباء. }
$$

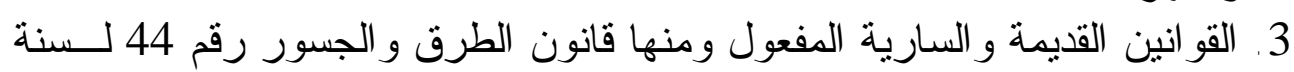

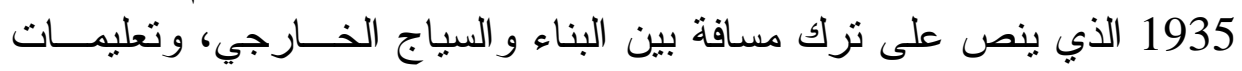

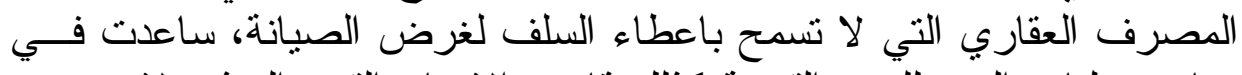

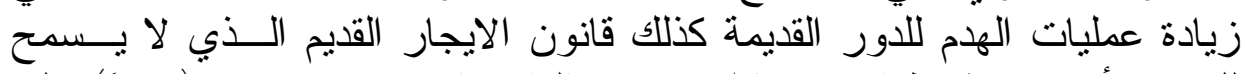

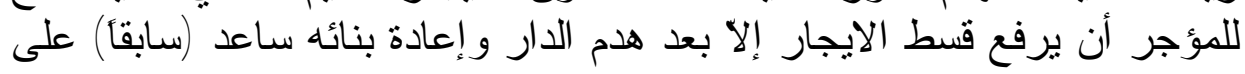

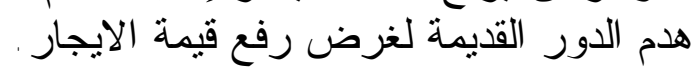

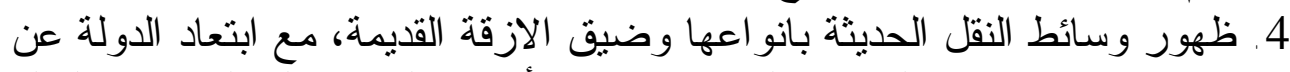

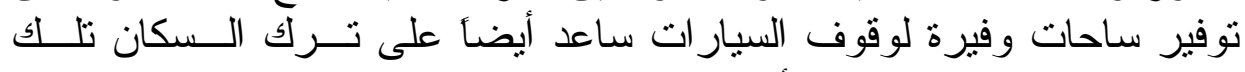
المناطق وتوجهمج للسكن في أطر اف المدينة. 
5. لم تقام الدولة معالجات حققية لسكنة المناطق التزاثية القديمة، أو تبدي إمكانية

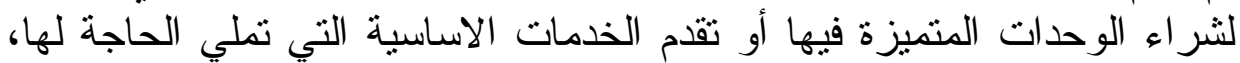

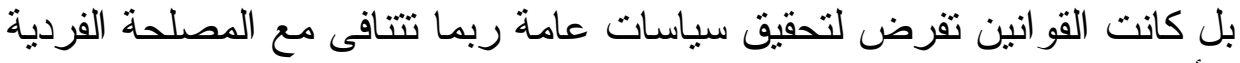

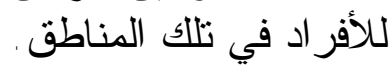

$$
\text { ثانياً - التوصيات }
$$

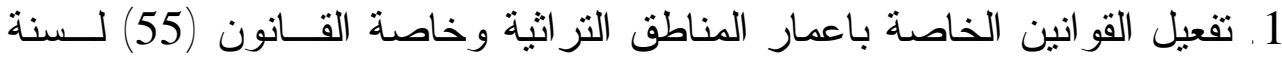

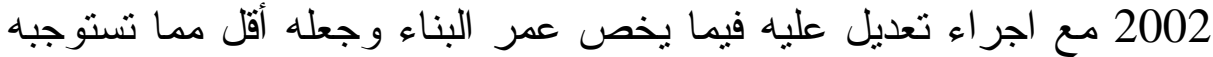

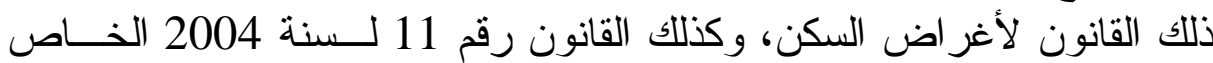

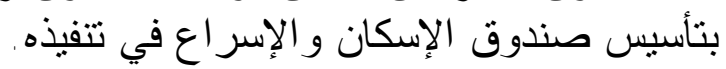

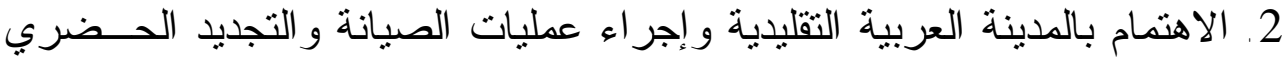
و استغلال المناطق المتهرئة فيها وذللك بإعادة ترميمها.

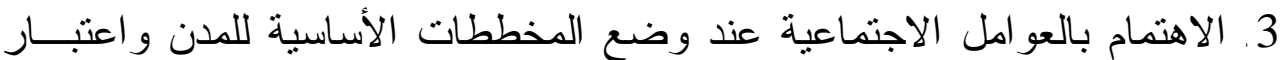

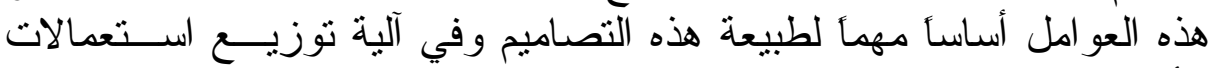

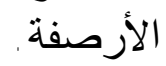

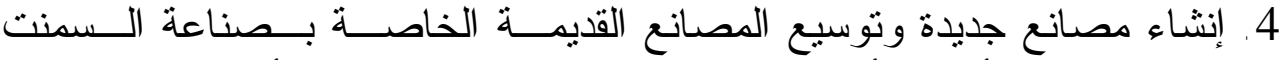

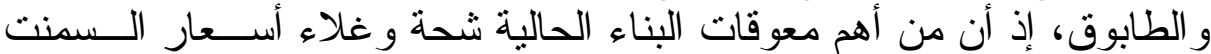

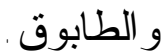

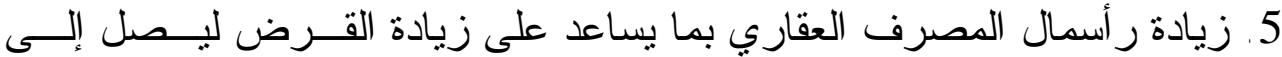

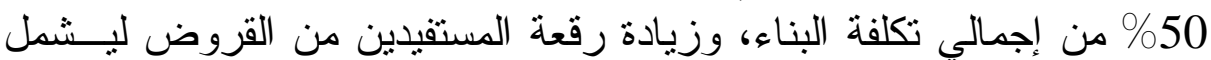

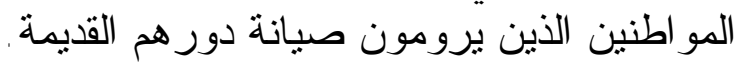

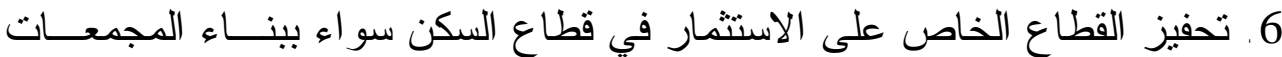
السكنية الكاملة أو تشييد معامل للمو اد الإنشائية المستخدمة في البناء النيناء.

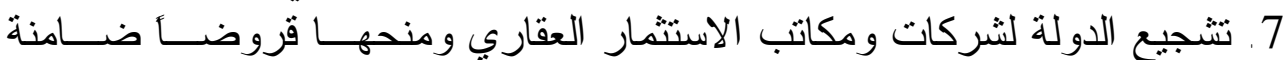

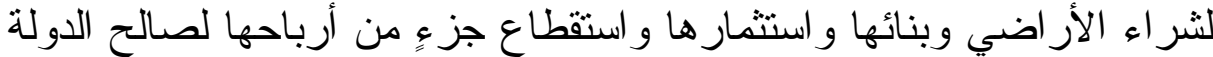

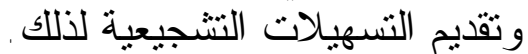
8. إعادة عمل الجمعيات التعاونية للإسكان أو تشكيل هيئات مشابهة للقيام بمهـام

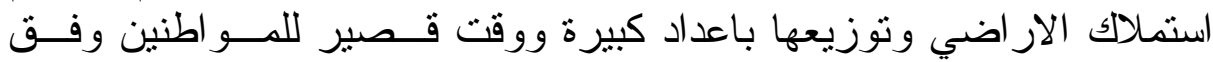
ضو ابط محددة. 9. النتسيق المستمر بين أعمال مديريات البلديات ومــديريات الطـــرق و الجـسور

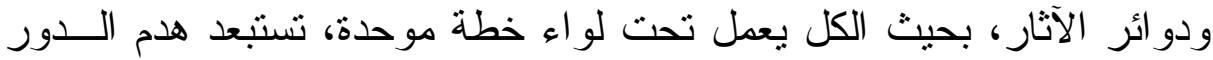

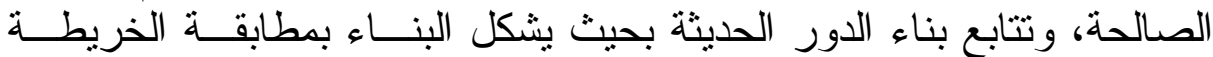

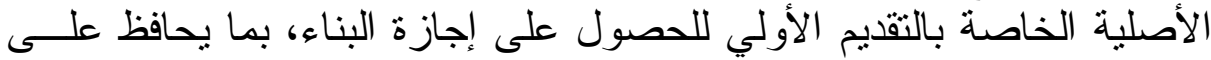

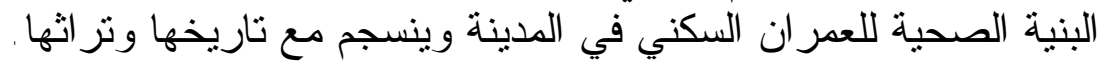




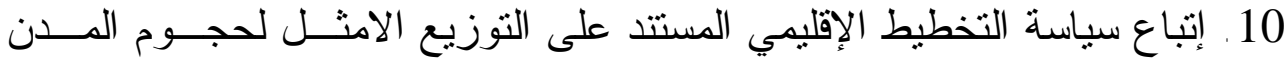

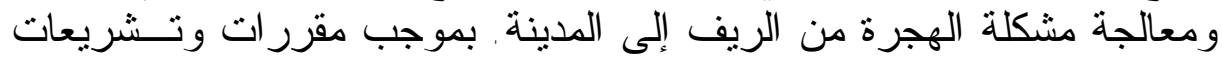
تخص ذللك.

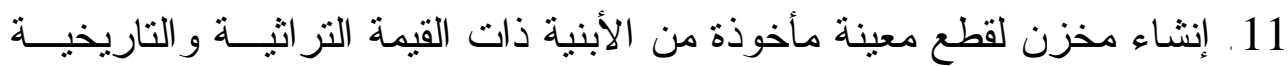

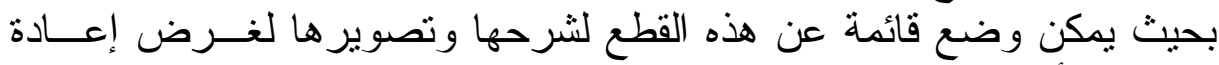

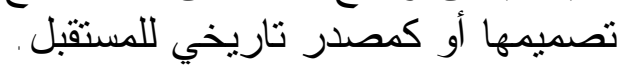

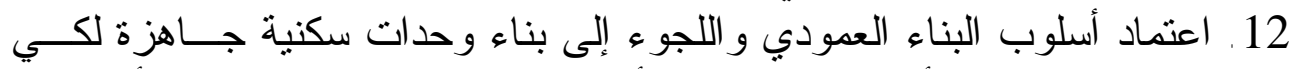

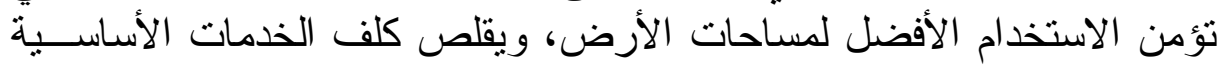
ويحسن بيئة المدن معمارياً.

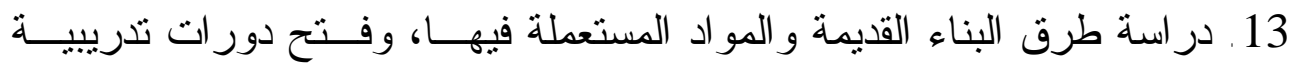

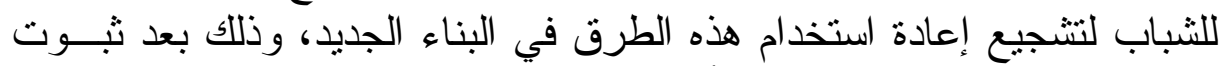

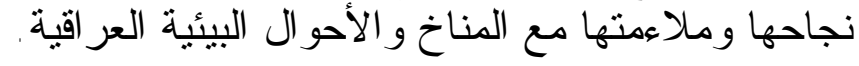

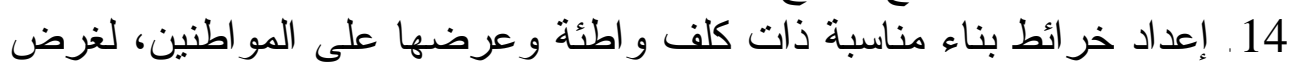

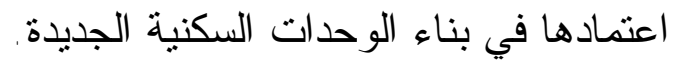

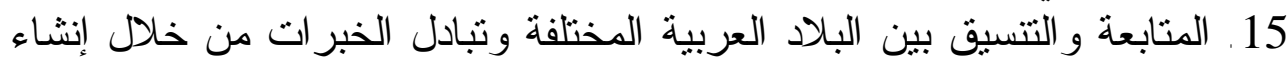

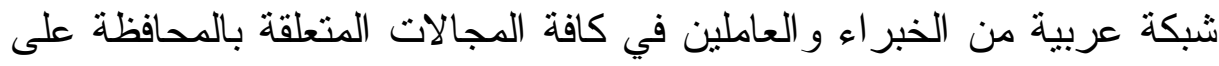
التز اث وصيانته وتخطيطه و إدارته .

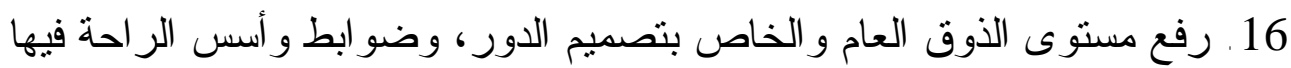

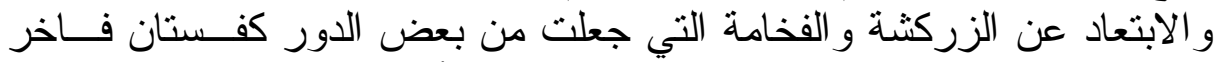

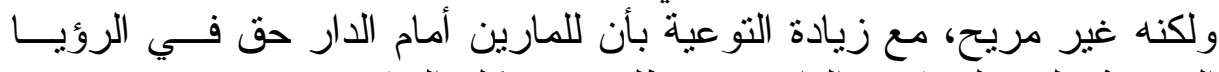

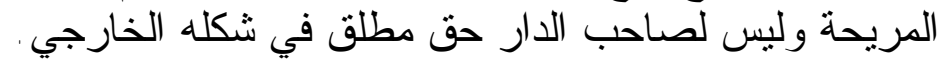

\section{أولاًا - المر اجع باللغة العربية}

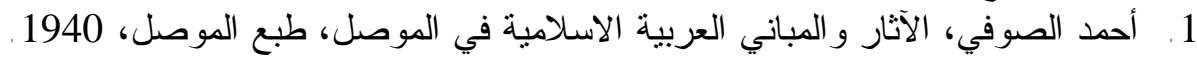

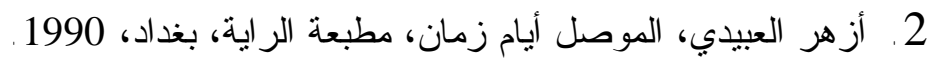

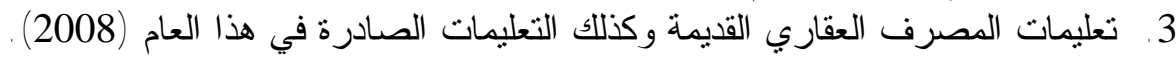

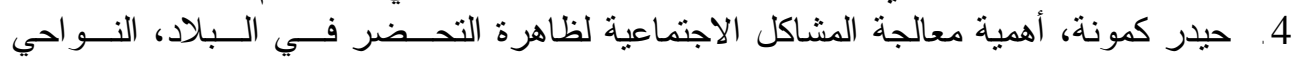

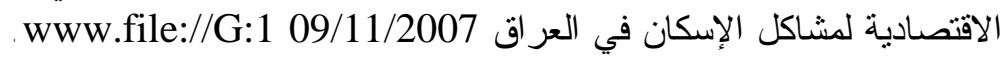

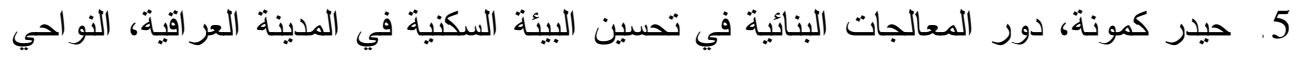

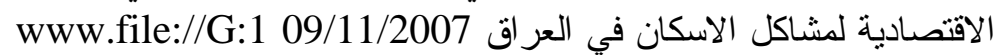
6. شهاب أحمد الفضلي، آفاق إستراتيجية: دور القطاع غير الحكومي في الاســتنمار الـسكني www.file://G:1 12/11/2007

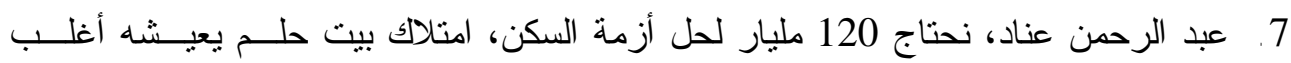

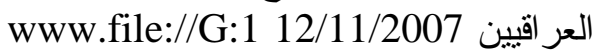
8. القانون رقم (44) لسنة 1935 المسمى قانون الطرق و الجسور والساري المفعول. 


$$
\text { 9. } 10 \text {. القانون رقم (55) لسنة } 2002 \text { المسمى قانون الخاسيس صناندوق الاسكان . }
$$

\section{ثانياً - المراجع باللغة الأجنبية}

1. Levfebvre, H., La Revolution Urbaine, Galimard, Paris, 1970, and Pensee Marxiste et Vilk, Gasterman, Paris 1972 .

2. Raouf, L. N., Housing in the third world, International Journal of Urban and Regional Research 9, 31985.

3. Lapidus, I.M., Muslim Cities in the Later Middle Ages, Cambridge, Mass, 1967. 